\title{
إلزامية تطبيق IFRS وأثره على جودة المعلومة المحاسبية والقوائم المالية -مع الإشارة إلى تجارب بعض المعلو الدول-
}

$$
\text { كلية العلوم الاقتصادية عبدالجليل }
$$

تخهف: تهدف هذه الورقة إلى إبراز أثز إلزامية تطبيق معايير التقارير المالية الدولية ( : (IFRS International Financial Reporting Standards المعلومة المحاسبية و إعداد القو ائم المالية. فأغلب الدول التي التزمت بتطبيق IFRS

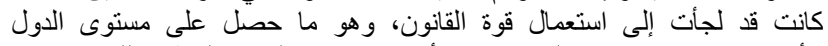

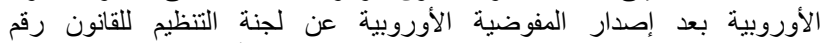

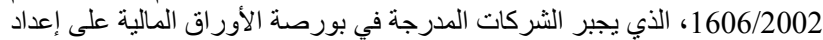

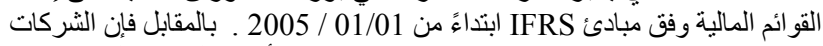

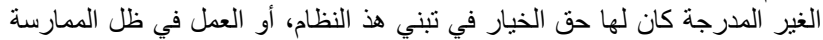

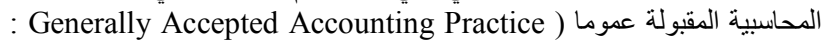
GAAP). والملاحظ أن الدول قد تباينت من حيث الآثار الناجمة عن التطبيق الإنيق

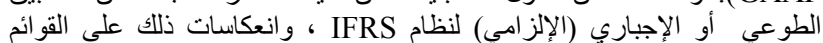

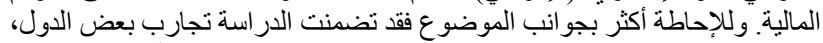

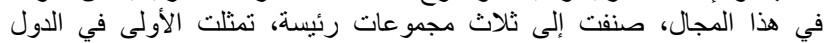

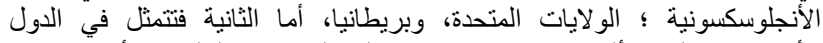

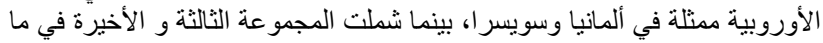

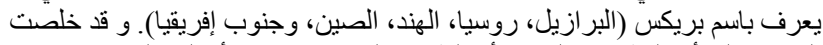

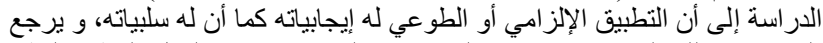

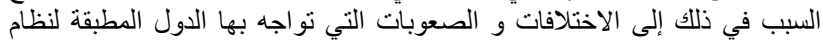

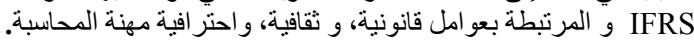

\section{مقدّمة Abstract:}

$$
\begin{aligned}
& \text { إن استبدال نظام المحاسبة } \\
& \text { (GAAP) } \\
& \text { الولايات المتحدة الأمريكية، و في } \\
& \text { الكثير من دول العالم المنطور، } \\
& \text { لاليل واضح على ما يجري من } \\
& \text { تغيرات هامة في توجهات } \\
& \text { الاقتصاد العالمي نحو نرسيخ نظام } \\
& \text { جديد لإعداد التقارير المالية الدولية } \\
& \text { يكون أكثر شمولية و تماثلا في ما } \\
& \text { بين الاقتصادات المختلفة. }
\end{aligned}
$$

\section{The aim of this paper is to shed light of the effect of mandatory IFRS} (International Financial Reporting Standards) on information accounting quality and the preparation of financial statements. Most of the countries that are concerned with the application of IFRS have used Law as a mandatory mean for such purpose. The European Commission has issued a statement No 1606/2002 that oblige listed companies in the stock market to adopt IFRS starting from 01/01/2005. On the other hand, unlisted companies have the choice either adopting IFRS, or working within the GAAP(Generally Accepted Accounting Practice). As a matter of fact, there have been two kinds of adopting IFRS: mandatory and voluntary. Therefore, the kind of IFRS adoption has had different effects on those concerned countries regarding their financial statements. In addition the study contains certain countries' experiences from which three groups have been selected: two from Anglosaxon countries represented by USA and UK, and two other countries from Europe, like Germany and Switzerland, whereas BRICS represents the last group (Brazil, Russia, India, China, and South Africa). The conclusion shows that regardless of the type of IFRS adoption, there are always advantages and disadvantages sides as far as its application is concerned, and the reason behind all that is related to regulations, cultural, and accounting profession differences.

2016 جامعة الإخوة منتوري قسنطينة، الجزائر (C) 
إن الاعتتاء بإحداث تغييرات في البعض من المبادئ المحاسبية، في بداية القرن الو احد و العشرين، مفاده

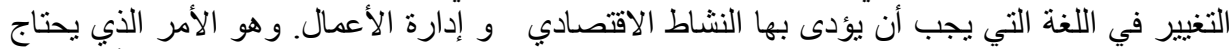

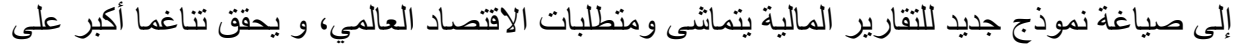

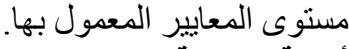

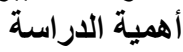

تهنت المحاسبة، باعتبارها نظام فرعي لا يتجزأ عن نظام إدارة المعلومة بالمنظمة، بإعداد التقارير

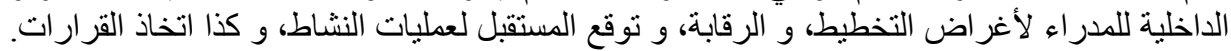

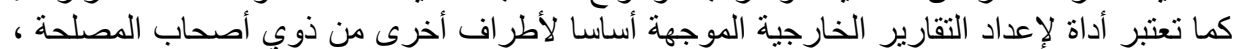

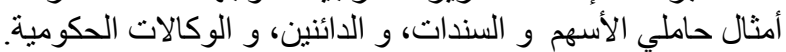

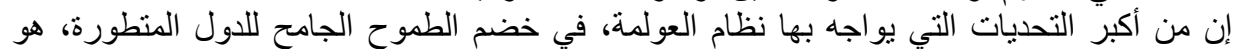

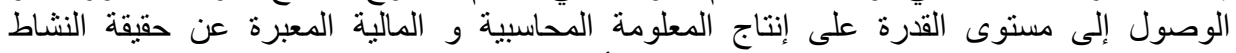

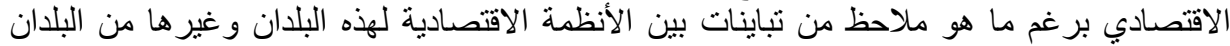

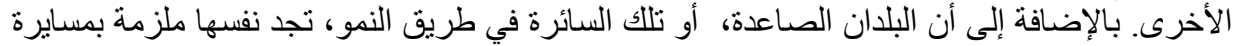

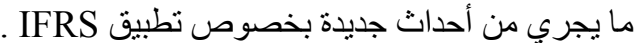

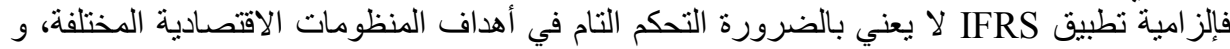

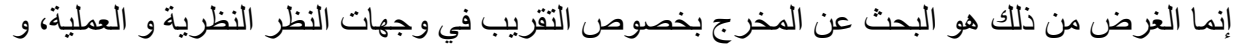

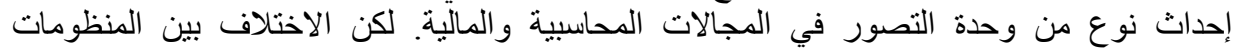

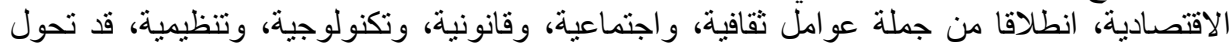

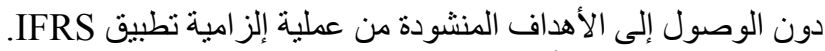

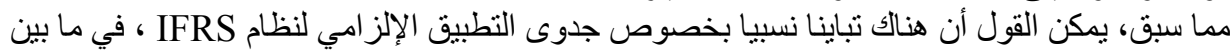

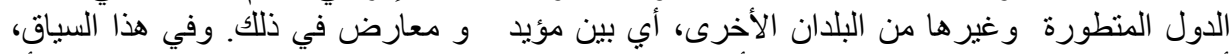

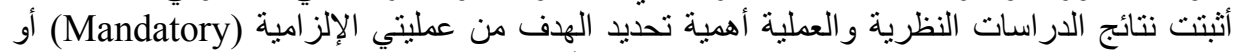

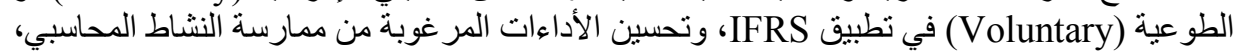

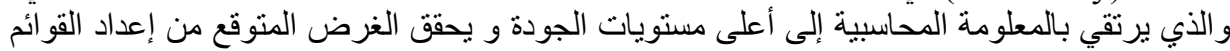

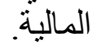

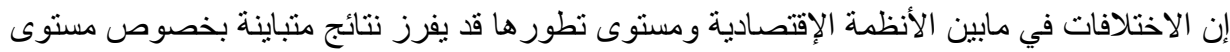

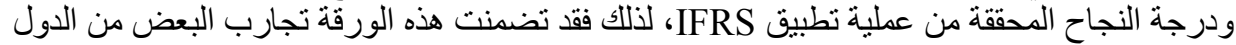

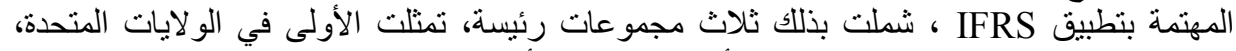

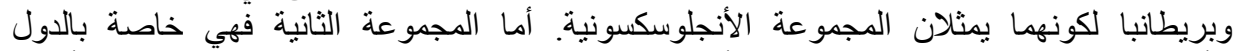

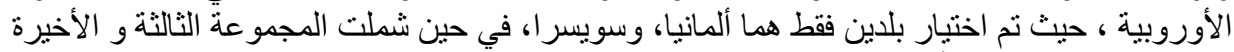

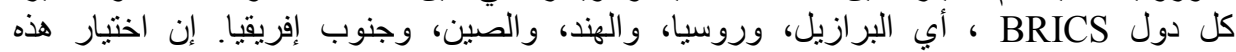

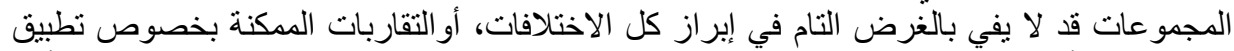

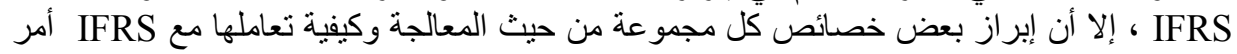

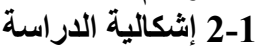

من المنطلقات السابقة تتحدد إثكالية الدراسة ، ضمن هذه الورقة ، من خلال السؤال الرئيس التالي، و

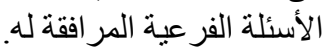

-ما هي الآثار الناجمة عن إلزامية تطبيق IFRS من منظور تحسين الجودة للمعلومة المحاسبية

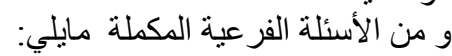
- كيف يعمل نظام IFRS من أجل ضمانة الأنس التحسين في جودة المعلومة المحاسبية؟ وماعلافته بتحسين

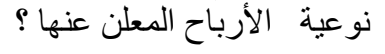


- ما أثر تطبيق IFRS على المؤشرات المالية المستتبطة من القو ائم المالية؟

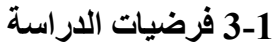

- تؤدي إلزامية تطبيق IFRS بالنسبة للثركات المدرجة في البورصة إلى تحسين جودة المعلومة

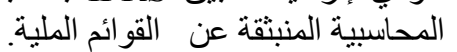

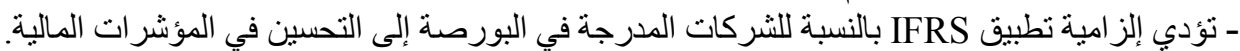

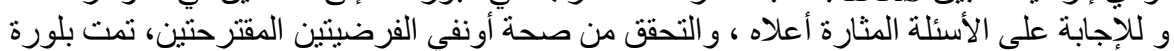

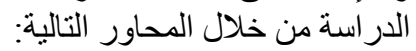

ـ تطور فكرة IAS /IFRS في ظل الأنظمة التقليدية، و ضمن كنف الثركات المدرجة في بورصة

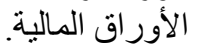

ـ تحديد مرتكزات IFRS من منظور مشكلات الاختلاف في التطبيق، و القيمة العادلة. ـ أثر IFRS على جودة كل من المعلومة المحاسبية ، و المؤشرات المات المالية.

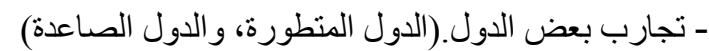
2- تطور المعايير المحاسبية و التقارير المالية الدولية (IAS /IFRS) في ظل الأنظمة المحاسبية التقليدية

1-2 لمحة تاريخية عن تطور المعايير المحاسبية الدولية ( International Accounting :

\section{(IAS Standards}

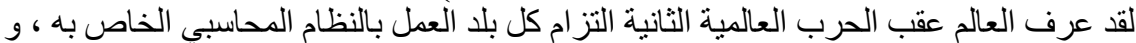

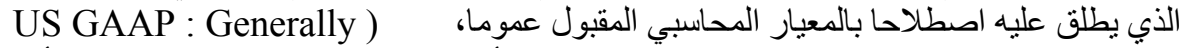
Accepted Accounting Standards

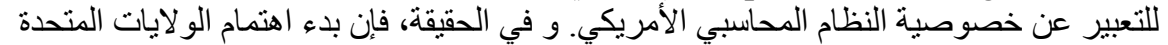

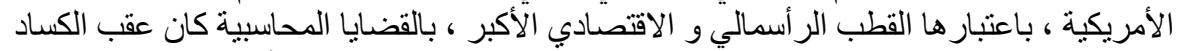

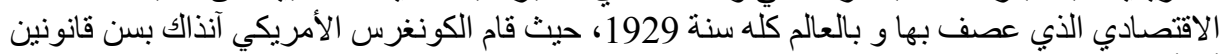

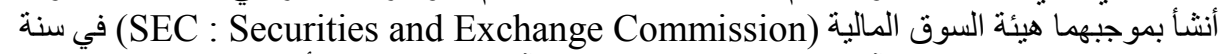

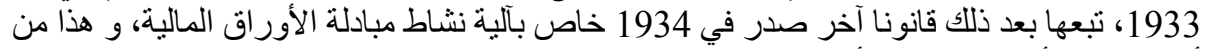

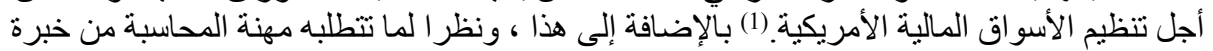

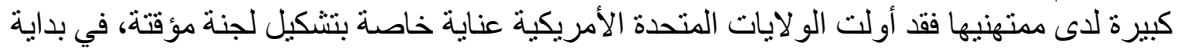

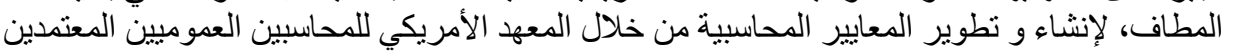

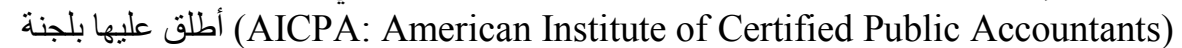
الإجر اءات المحاسبية ( CAP: Committee on Accounting Procedure) ، استطاعت هذه

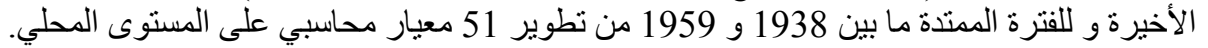

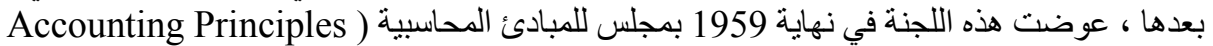

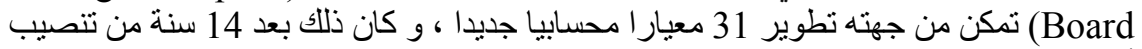
FASB: Financial ( أعضائه. (2) بعدهاو في سنة 1973 نم إنثاء مجلس المبارئل

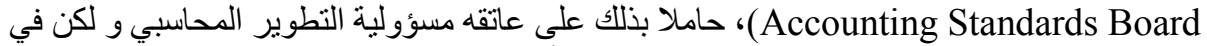
ظل وجود تتسيق دائم مع حامل الشعل و هو المعهد الأمريكي للمحاسبين العوميين المعتمدين المين

(AICPA)

IASC: International Accounting إرساء لجنة المعايير المحاسبية الدولية 1-1-2 (Standards Committe أنشئت لجنة المعايير المحاسبية الدولية بعد تظافر الجهود لمبادرات عديدة من أهمها المبادرة الني

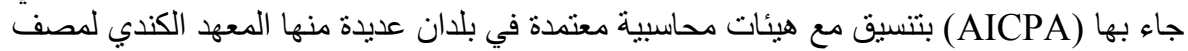


الخبر اء المحاسبين (CICA: Canadian Institute of Chartered Accountants)، و معهد

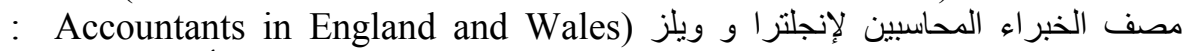
(ICAEW Institute Of Chartered Henry Alexander Benson

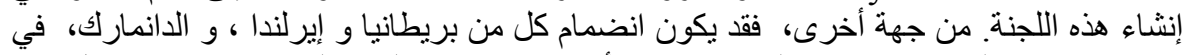

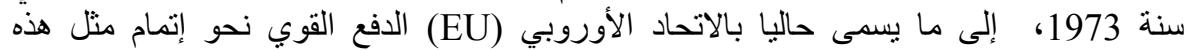

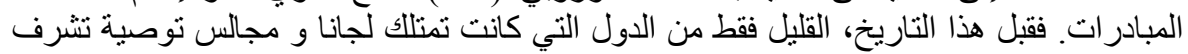

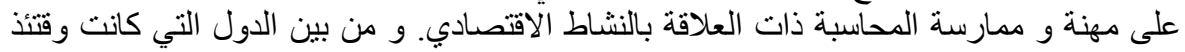

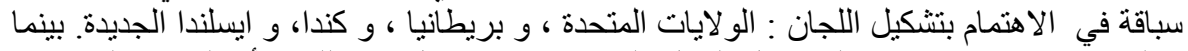

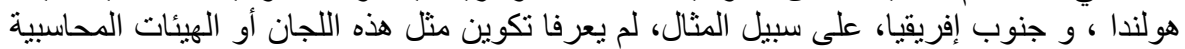

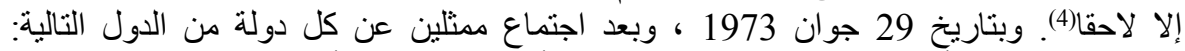

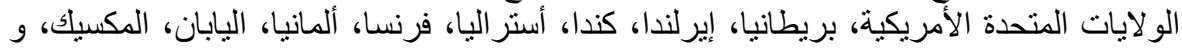

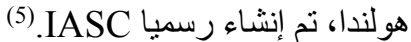

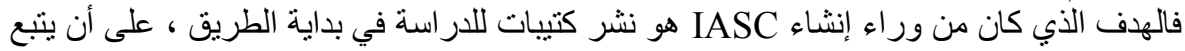

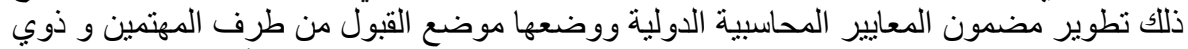

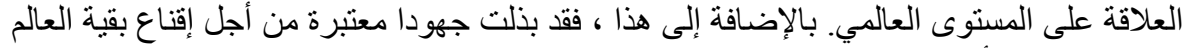

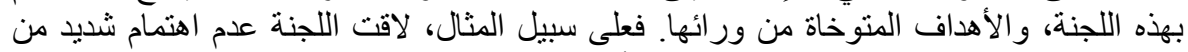

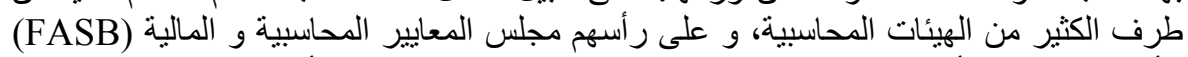

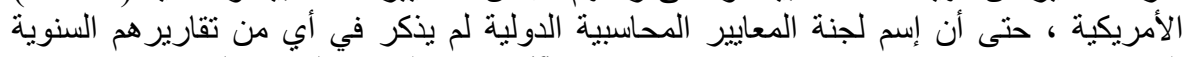

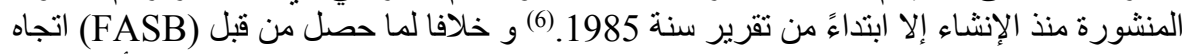

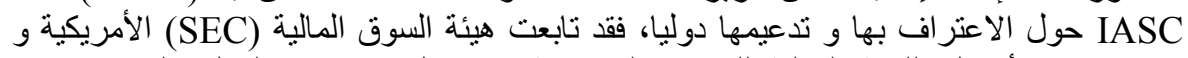

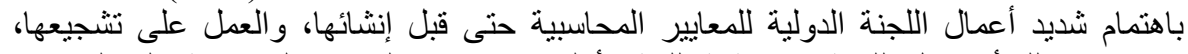
معتقدة في ذلك أن عمل اللجنة يعد بمثابة اللبنة الأولى نحو توحيد المعايير المحاسبية على المستوى لئى

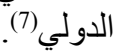

ففي عام 1974 ، أصدرت IASC مسودة لائحة حول المعيار الخاص بالقوائم المالية الموحدة،

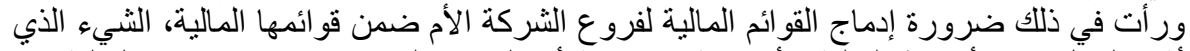

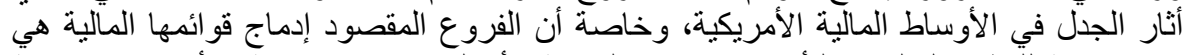

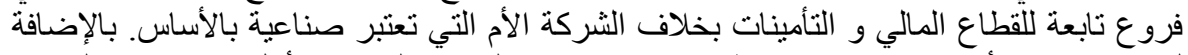

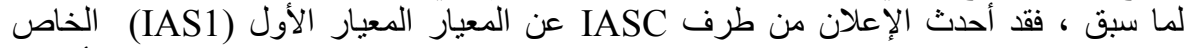

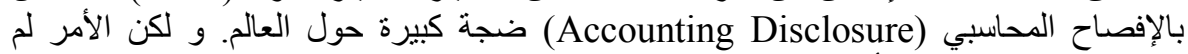

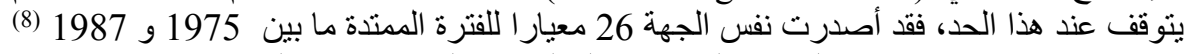
، و من بين ما تم إصداره المعيار المحاسبي الدولي ذو العلاقة بتغير السعر( Information IAS15 (Reflecting the Effects of Changing Prices

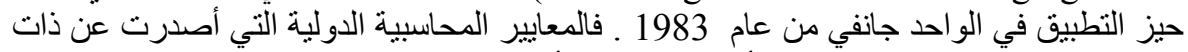

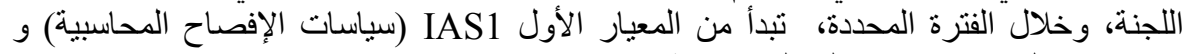
تتوقف عند المعيار IAS26 المتعلق بالاستثمار المبرات .

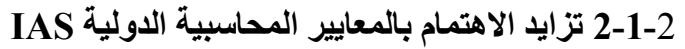

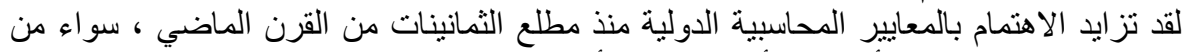

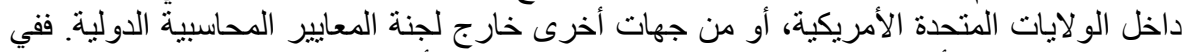

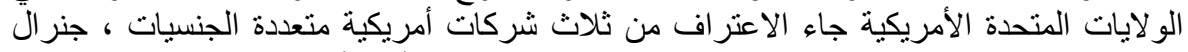

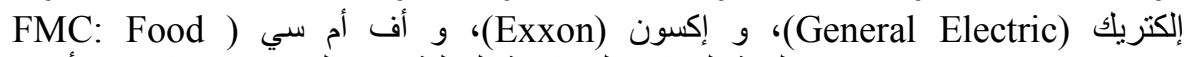
(Machinery Corporation 
بوجود انسجام بين المعايير المحاسبية الدولية الصادرة عن اللجنة و بين قو ائمها المالية. و هو الثيء توكيء

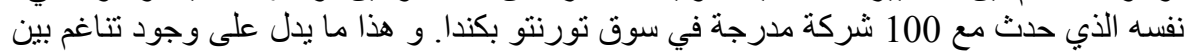

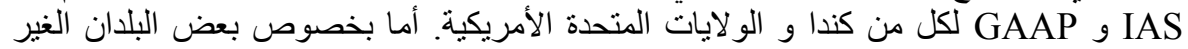

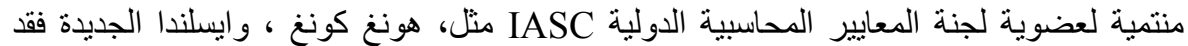

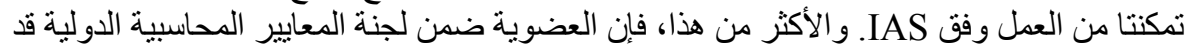

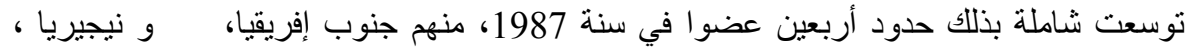

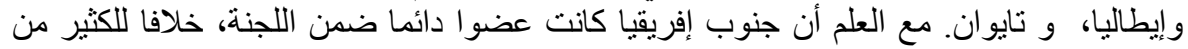

الدول، و لعبت دور ا بارزا في ترويج فكرة تبني المعايير الدحاسبية الدولية لدئ الدئ الدول النامية.

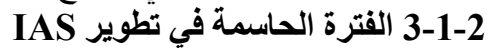

لقد ارتبط التطوير الحقيقي للمعايير المحاسبية الدولية بالتطور الفعلي للجنة المعايير المحاسبية

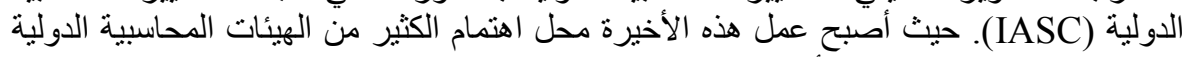

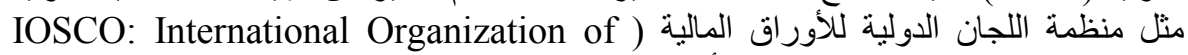

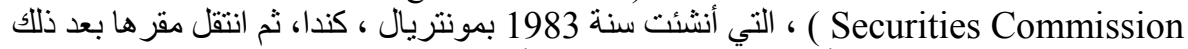

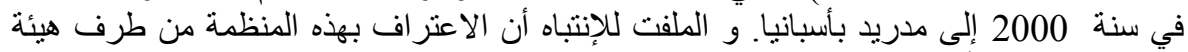

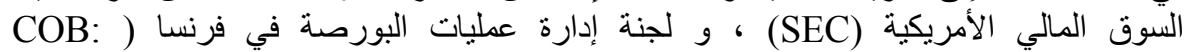
(Commission des Opérations de Bourse

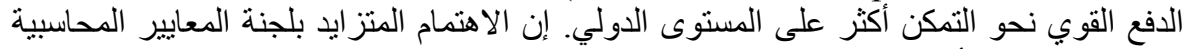

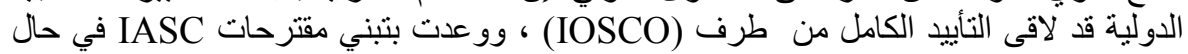

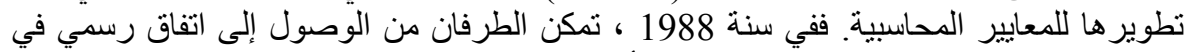

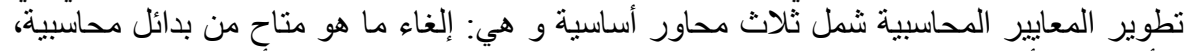

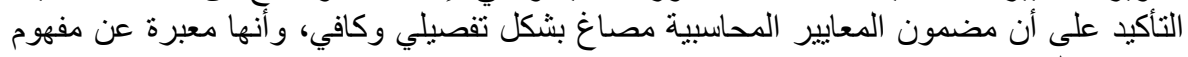

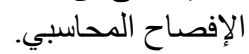

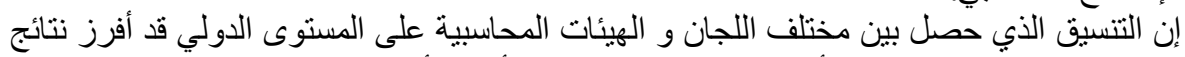

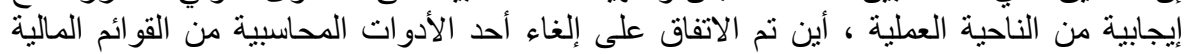

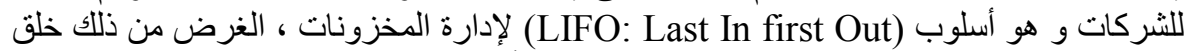

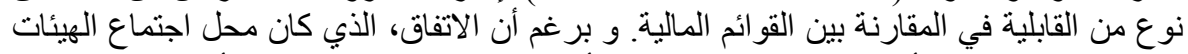

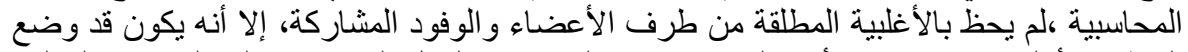

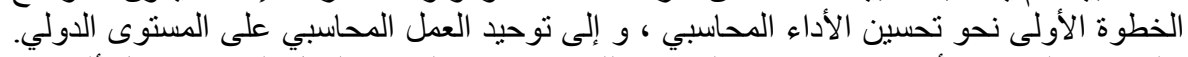

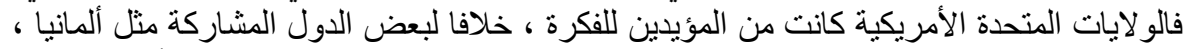

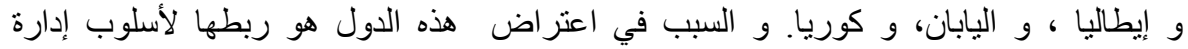

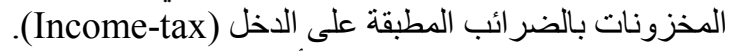

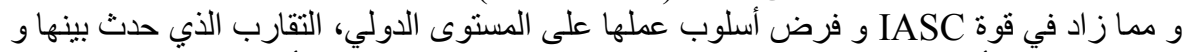

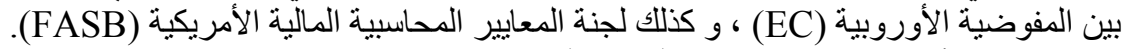

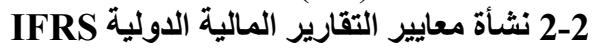

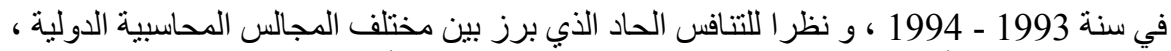

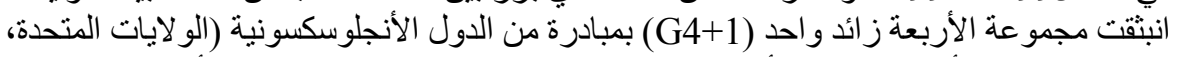

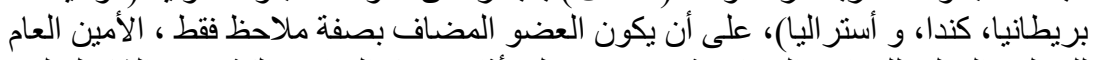

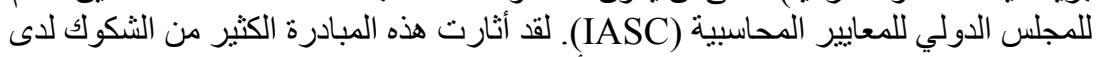

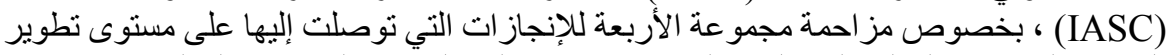

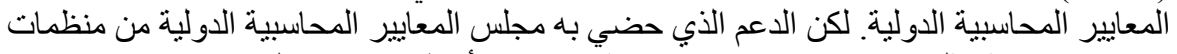

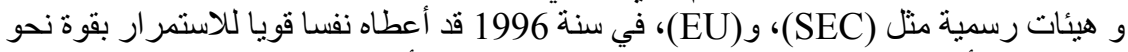
التطوير و الأخذ بزمام الريادة في هذا المجال. فلجنة سوق الأوراق المالية للو لايات المتحدة 


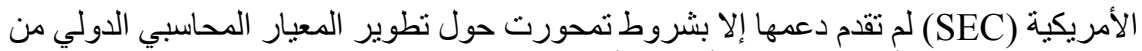

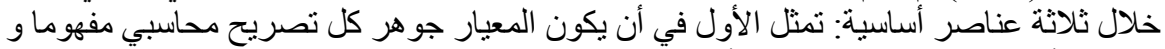

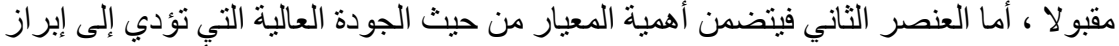

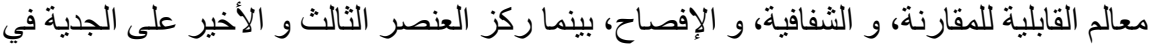

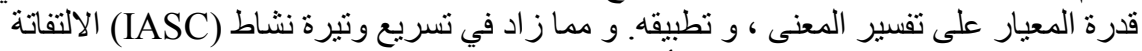

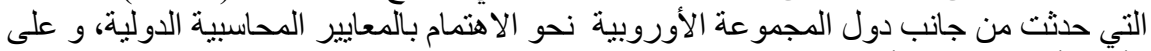

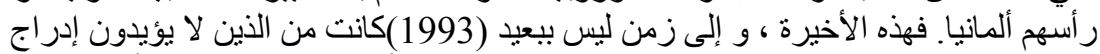

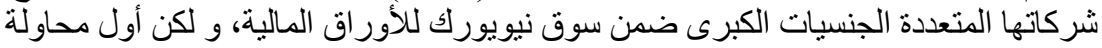

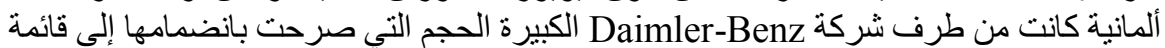

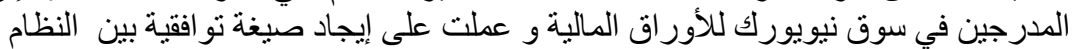

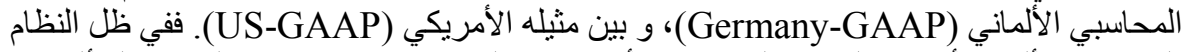

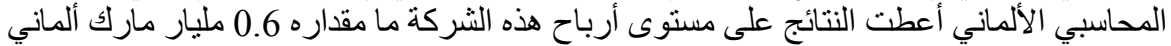

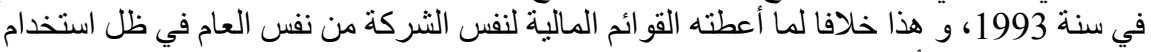

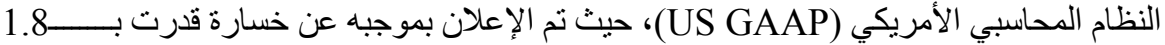

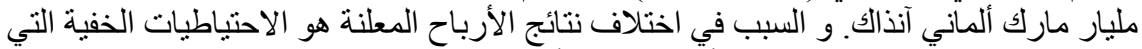

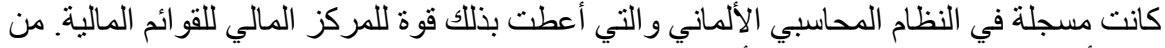

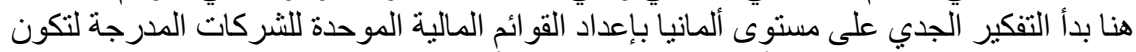

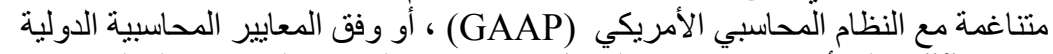

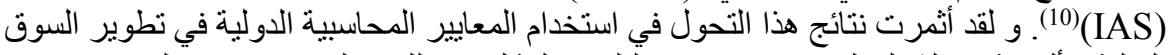

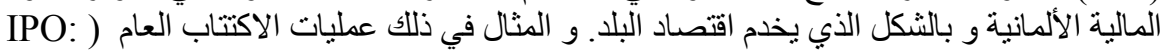

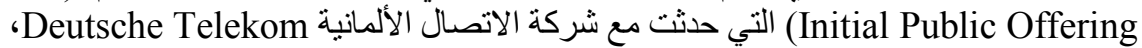

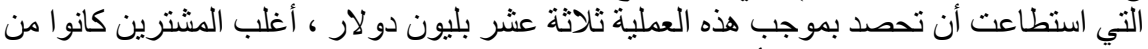

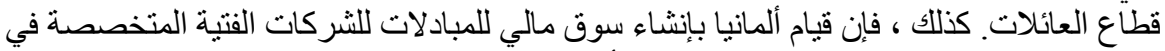

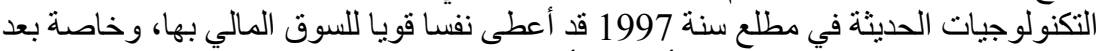

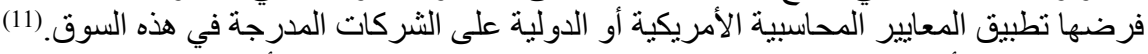

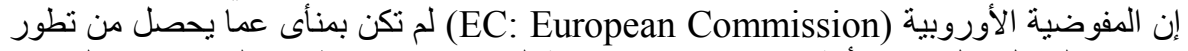

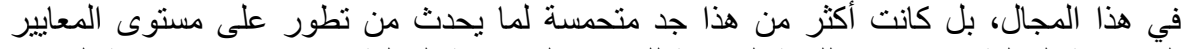

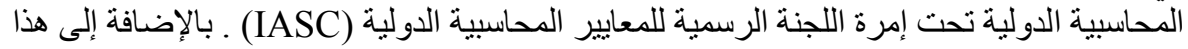

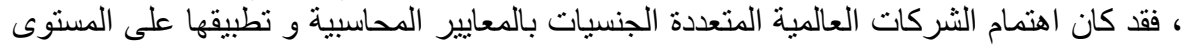

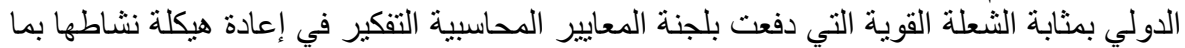

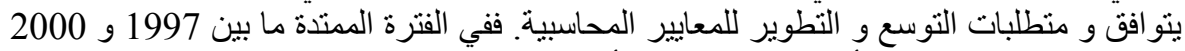

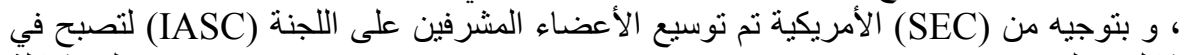

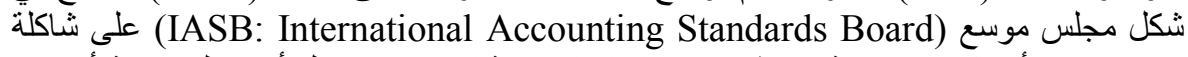

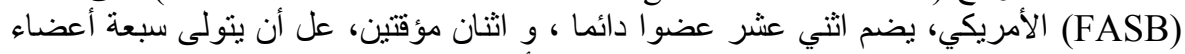

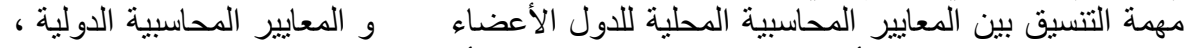

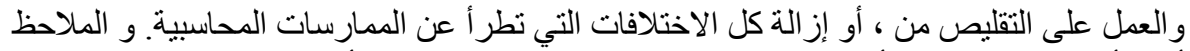

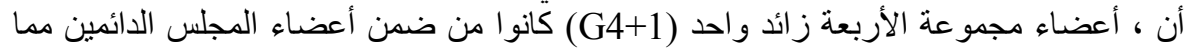

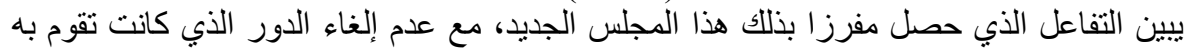

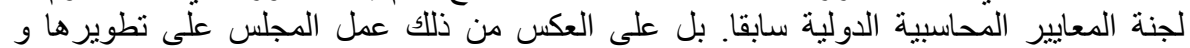

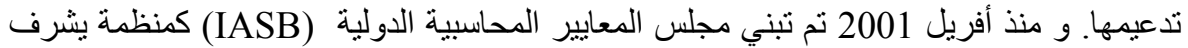

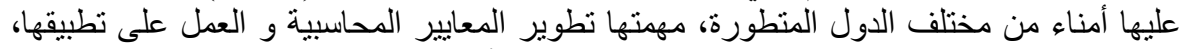
منبثقا عنها منظمة نطوير المعيار المحاسبي نعرف الآن باسم معايير التقارير المالية الدولية 


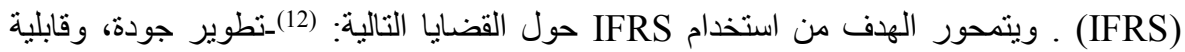

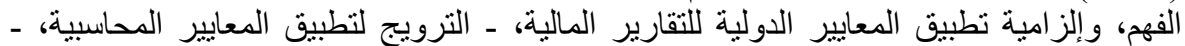

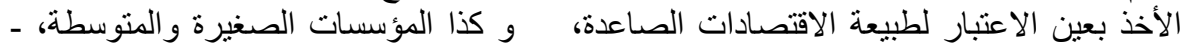
و إيجاد الحلول المثلوية للاختلافات الواضحة والمستعصية أحيانا بين IFRS و الأنظمة المحاسبية

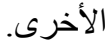

إن الانطلاقة الحقيقية التي ميزت بدء العمل وفق IFRS كانت في أكتوبر 2002 ،من خلال مذكرة

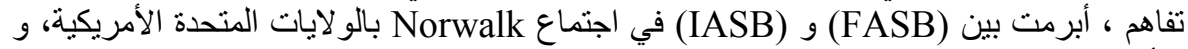

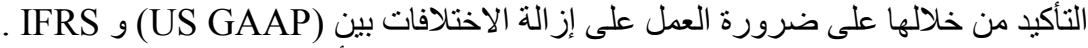

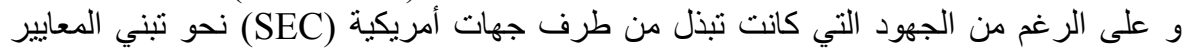

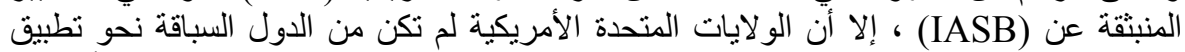

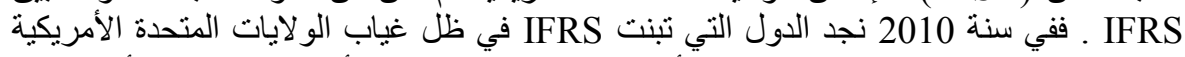

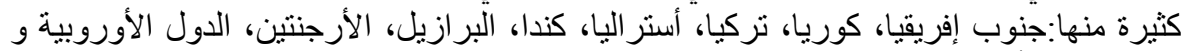

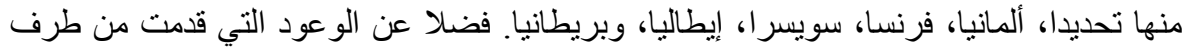

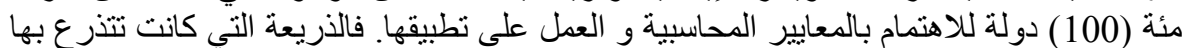

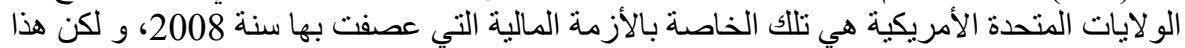

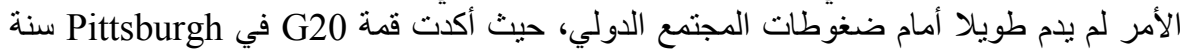

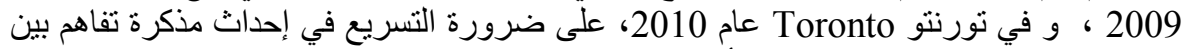

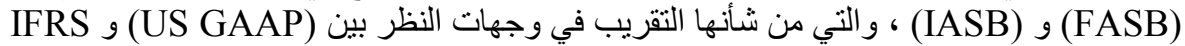

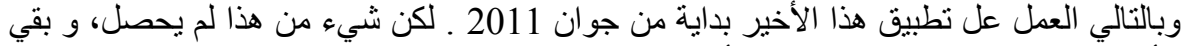

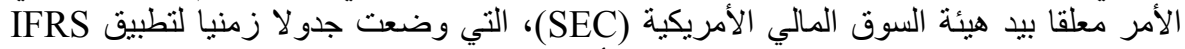

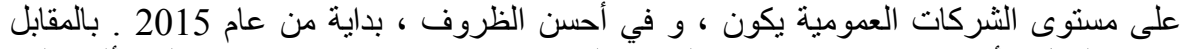

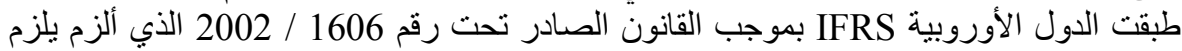

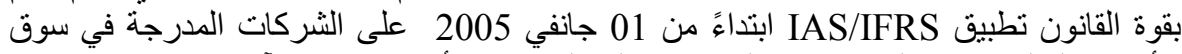

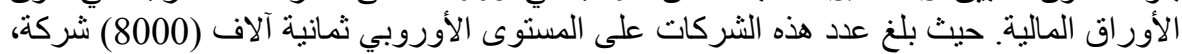

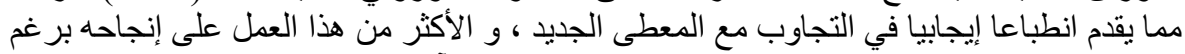

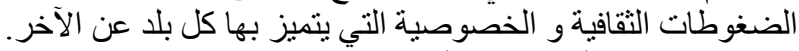

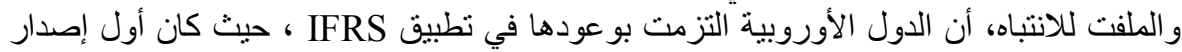

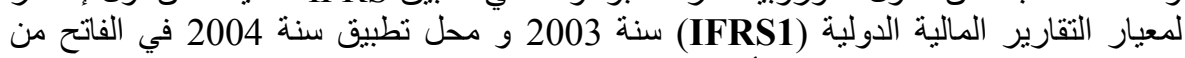
جانفي.ثم تلى بعد ذلك إصدارات أخرى، ففي سنة 2004،نم إصدار (IFS) (IFR2)، (IFRS3)،

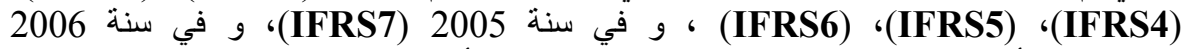

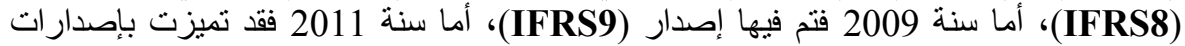

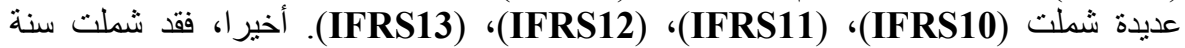

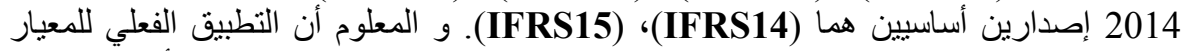

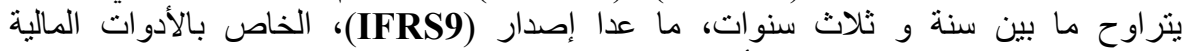
الذي أجلت مر اجعة بنوده في 2014 ليتم التطبيق الفعلي له ابتداءً من (Financial Instruments)

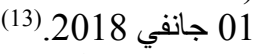

3- مرتكزات تطبيق (IFRS) و مفهوم القيمة المحاسبية العادلة

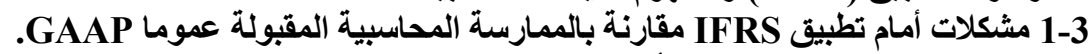

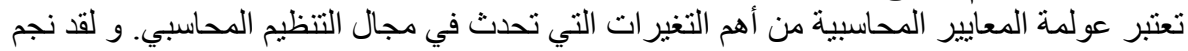

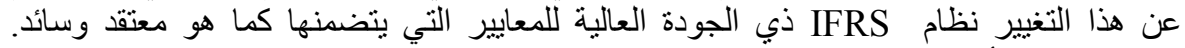

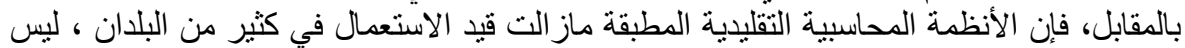

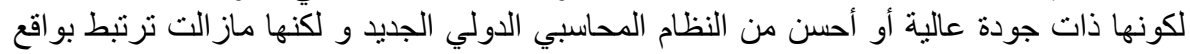




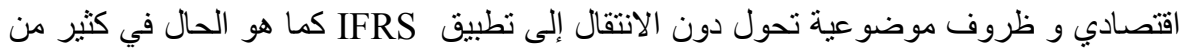

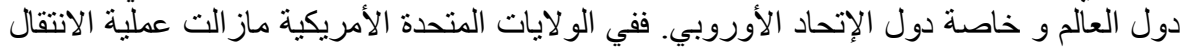

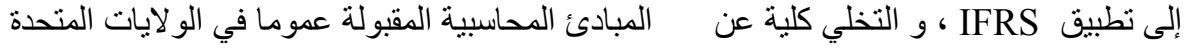

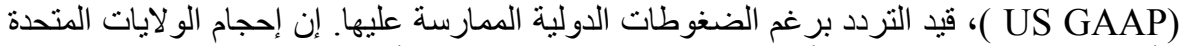

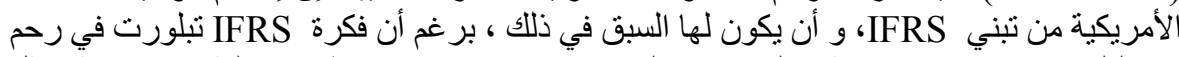

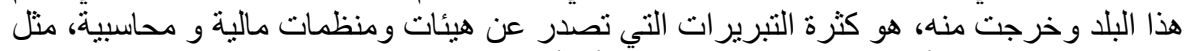

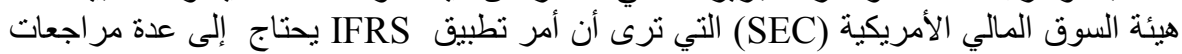

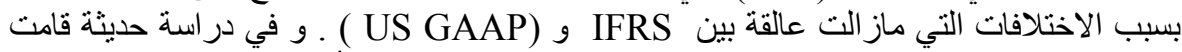

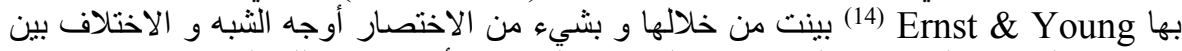

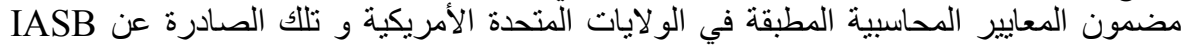

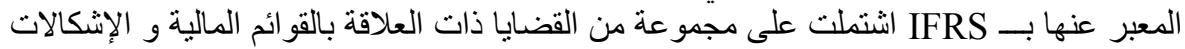

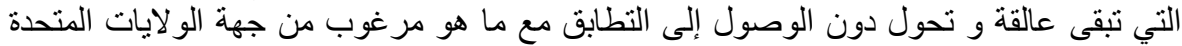

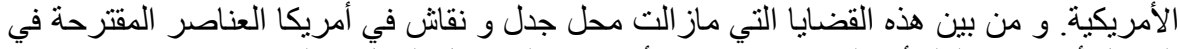
الجدول أدناه، مع العلم أنها ليست نهائية و قد أدرجت على سبيل المثال لا الحصر الحر

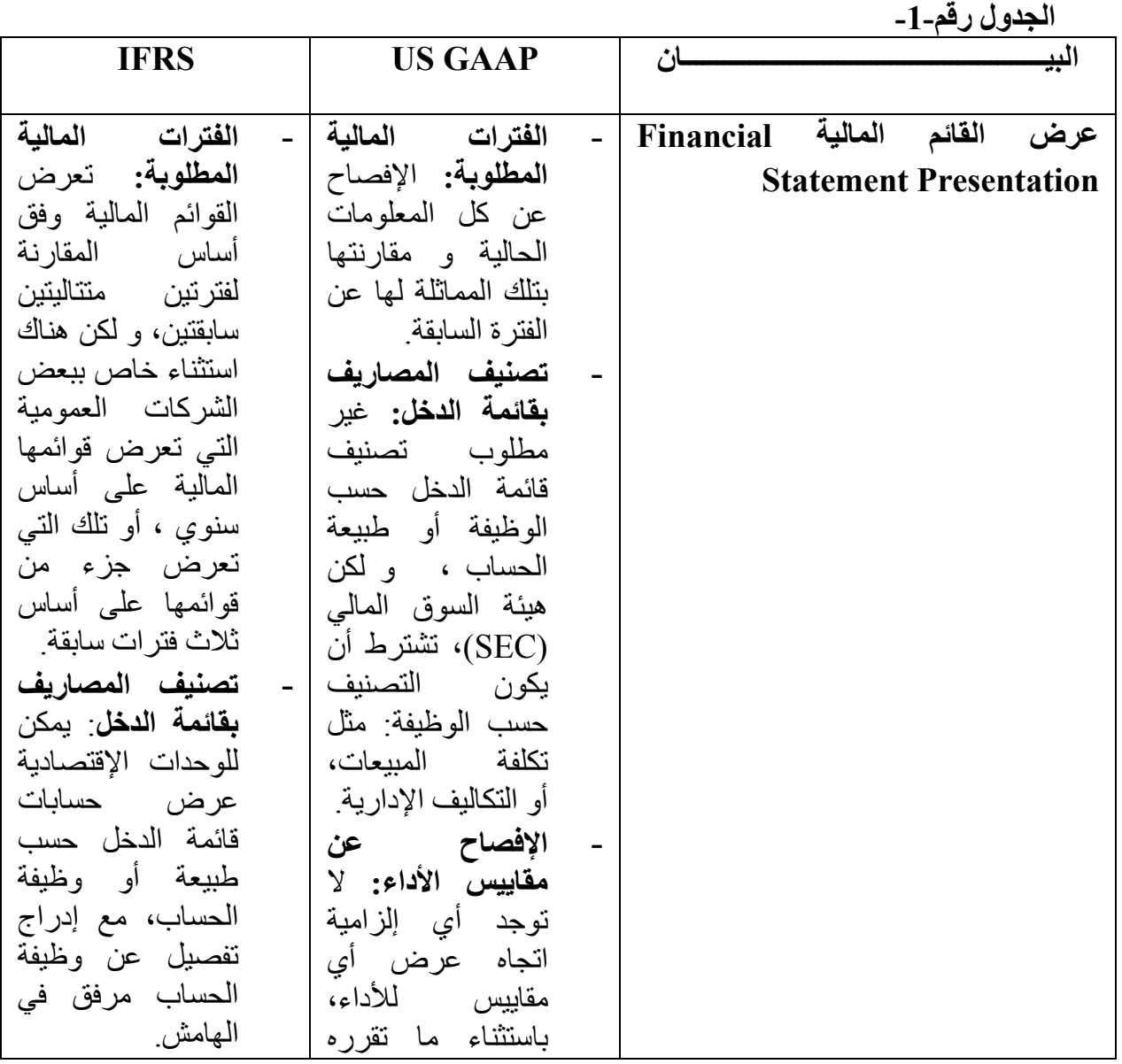




\begin{tabular}{|c|c|c|}
\hline 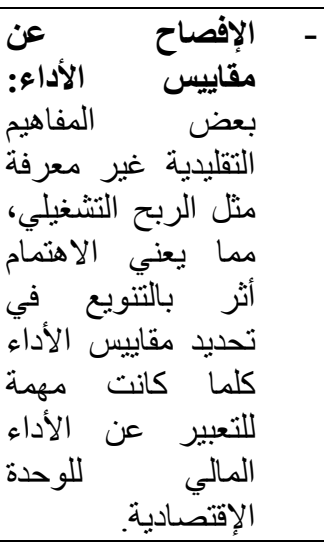 & 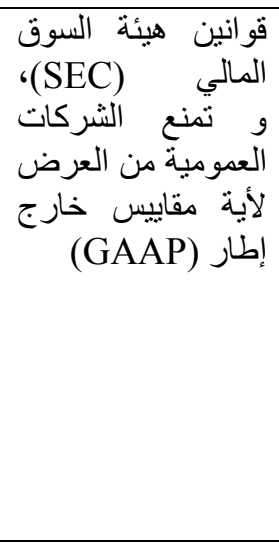 & \\
\hline 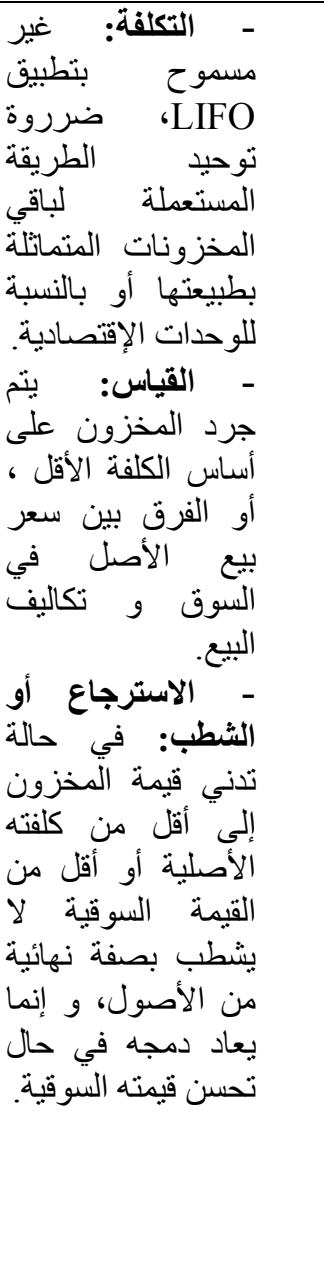 & 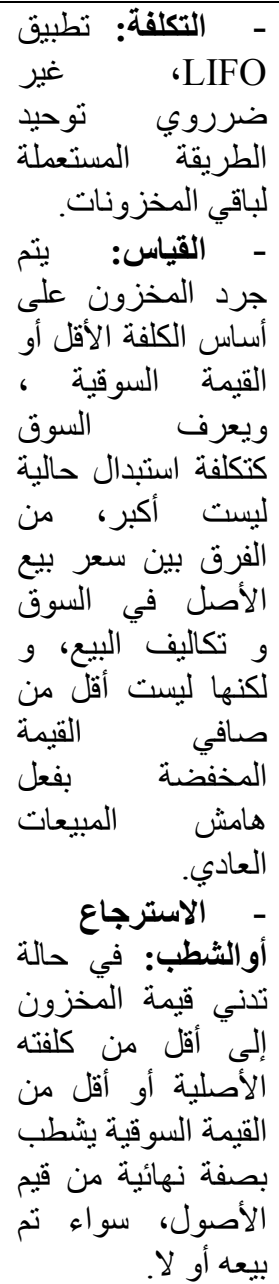 & المخزونات Inventories \\
\hline
\end{tabular}




\begin{tabular}{|c|c|c|}
\hline 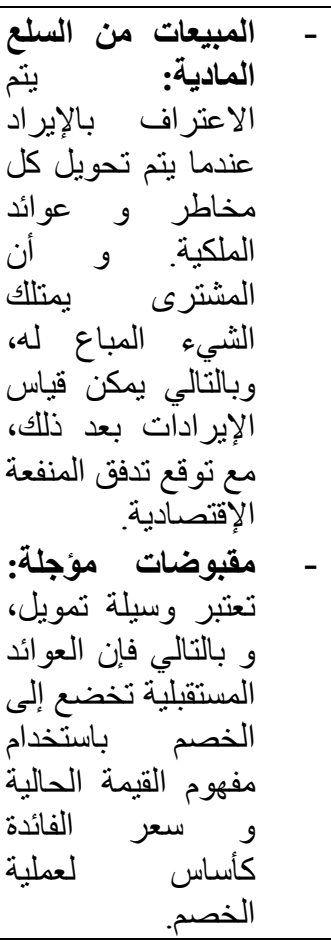 & 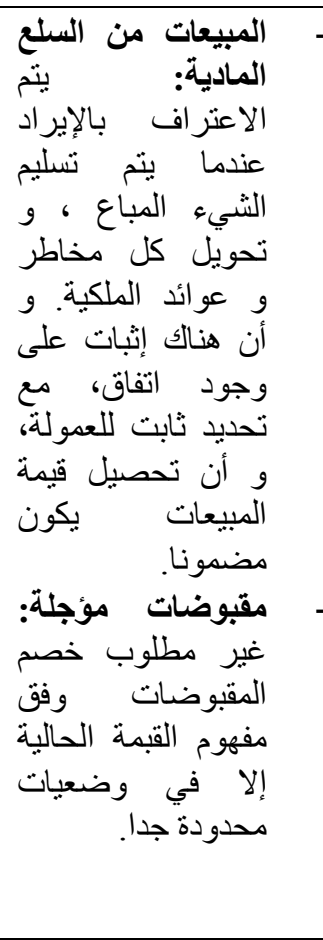 & $\begin{array}{r}\text { الاعتراف بالإير ادات } \\
\text { Recognition }\end{array}$ \\
\hline 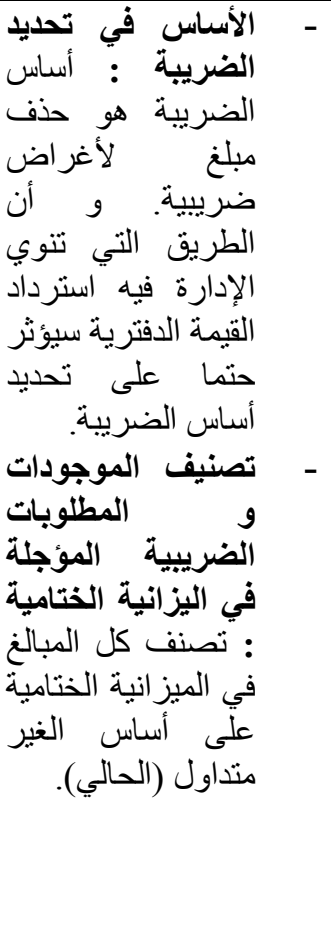 & 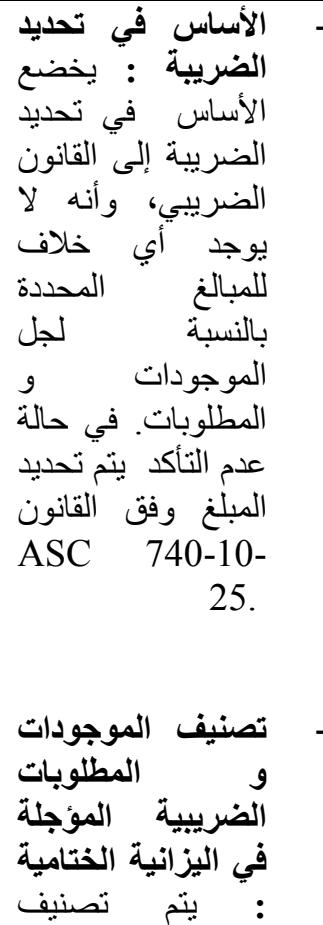 & الضر ائب على الاخل Income Taxes \\
\hline
\end{tabular}




\begin{tabular}{|c|c|c|}
\hline & المنداول المتناداً إلى غبي & \\
\hline 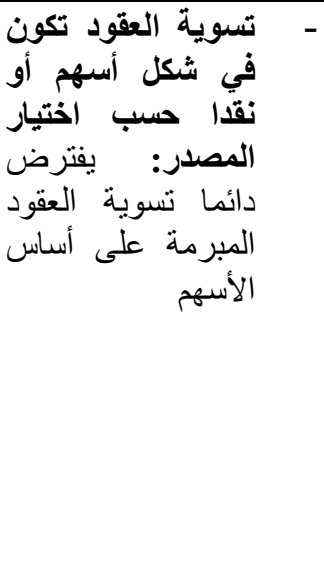 & 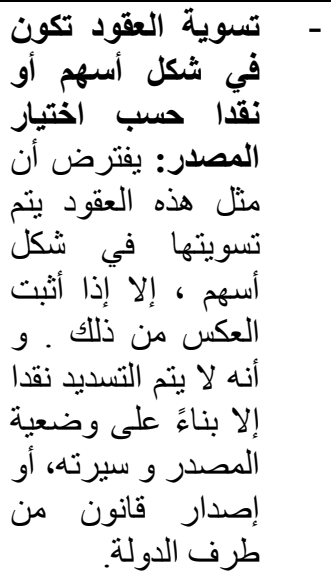 & 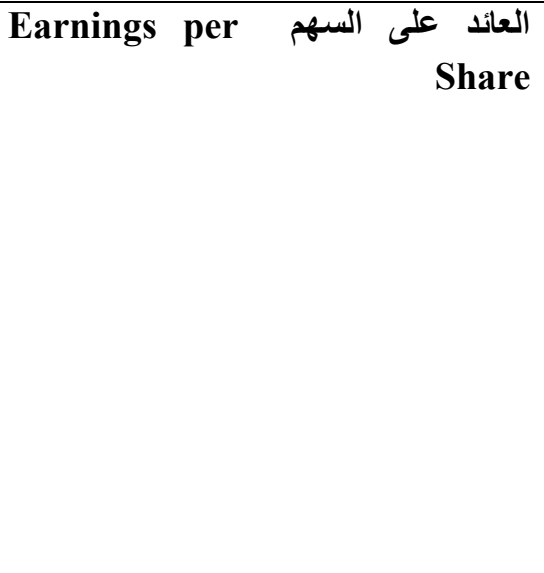 \\
\hline
\end{tabular}

Source: Ernst \& Young LLP, (2013), US GAAP versus IFRS:The basics, (http://www.ey.com/Publication/vwLUAssetsAL/IFRSBasics_BB2648 6Nove mber2013/\$FILE/IFRSBasics_BB2648 6November2013.pdf), Web Sept 2014.

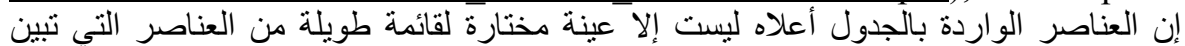

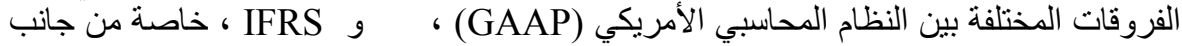

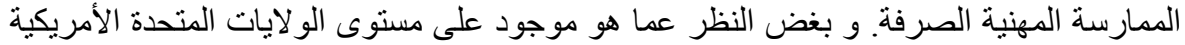

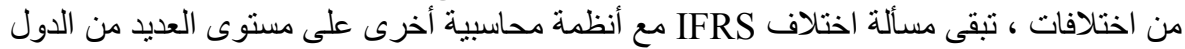

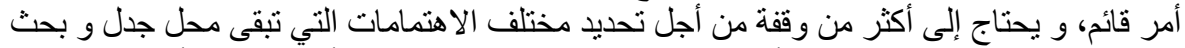

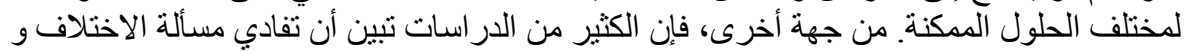

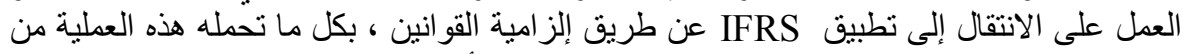

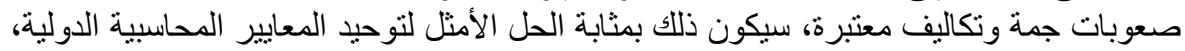

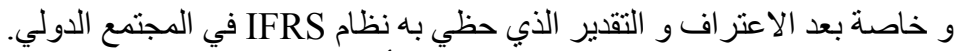

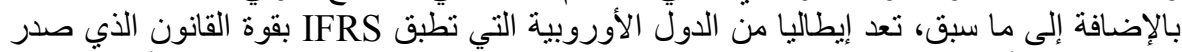

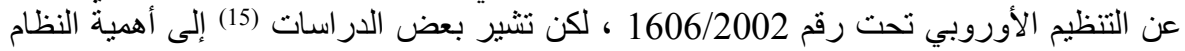

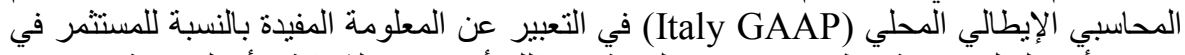

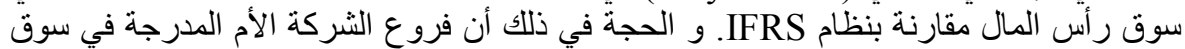

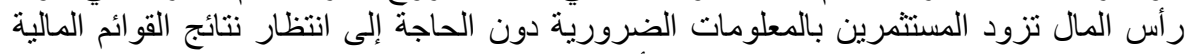

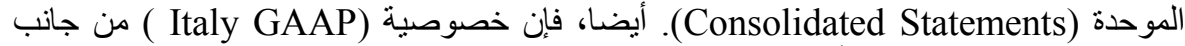

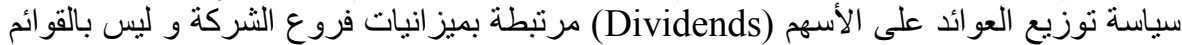

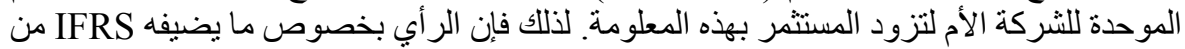

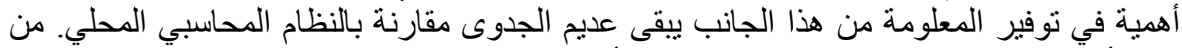

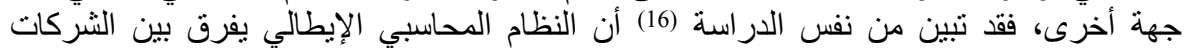

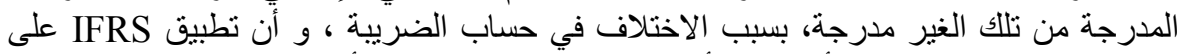
الثركات المدرجة يضع مسألة إدارة أرباح الثركة موضع الثنك أو الريبة من منظور مفنتئي 


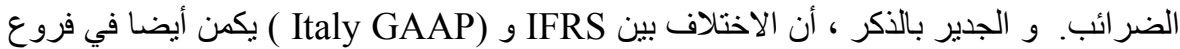
الثركات الغير معدة للبيع أنها تقيم على أساس التكلفة التهان التاريخية ، أو حقوق الملكية وفق المبادئ

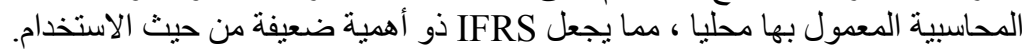

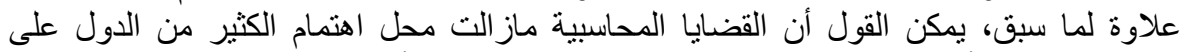

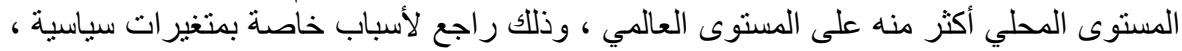

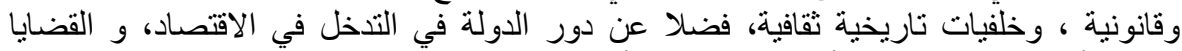

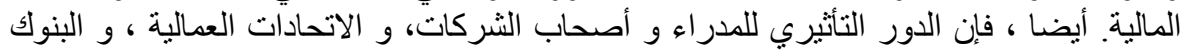

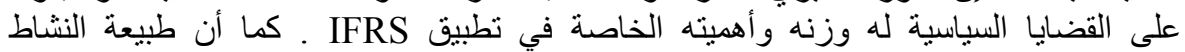

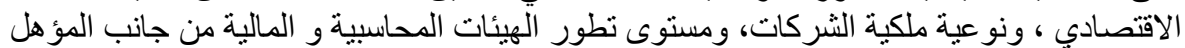

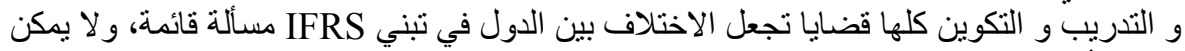
إز التها أو التقليل منها إلا بإز الة الاختلافات المؤسساتية ذات العلاقة بالجو التباتب التنظيمية و القانونية.

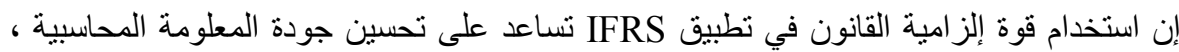

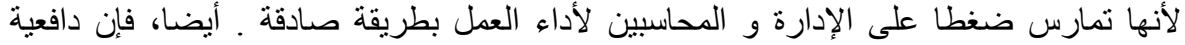

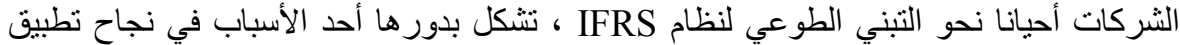

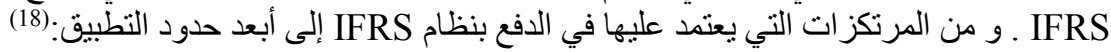

ضرورة نعاون المهنيين المكلفين بوضع المعيار مع الأكاديميين من أجل توحيد الرؤى للقضايا

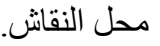

الاهتمام بالقيمة العادلة (Fair-value) المحاسبية مما قد بساعد على زيادة ثقافة إعداد القوائم

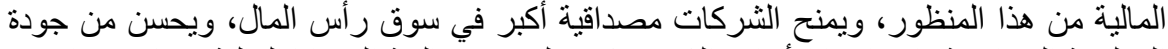

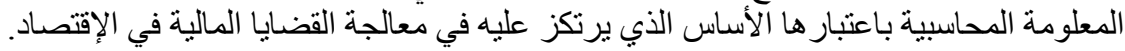

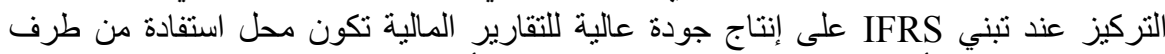

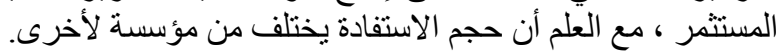

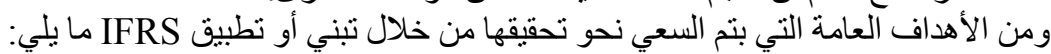
التوجه نحو العالمية في ممارسة نشاط التها الأعمال. تحقيق مبدأ الثفافية في الإعلان عن الأرباح الأرياح

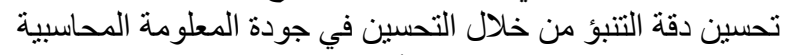
التخفيض في الكلفة (بتجاوز مسألة ازدو اجية استخدام المعايير المحاسبية) تحسين مسنوى الرقابة الداخلية للنشاط

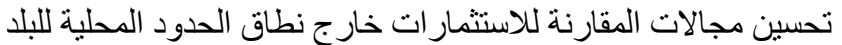
التخفيف من حجم اللوائح و التعليمات المعتمدة. حاليا، يتضمن 2000 IFRS صفحة، بينما بتضمن ذللك في ظل (US GAAP) 25000 صنحة. تحسين جودة المعيار المحاسبي، وتحقيق مبدأ القيمة العادلة.

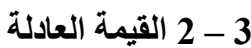
لقد تزايد الاهتمام بقياس القيمة العادلة (Fair Value) كأساس مستهدف لاستخدامه في إعداد

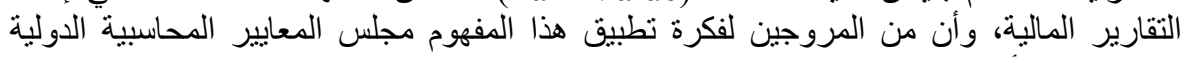

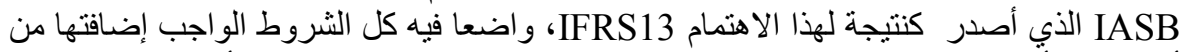
أجل جودة أحسن للتقارير المالية. و مما زاد في الاهتمام حول هذا الموضوع الأزمة المالية 2008 
التي عجلت في إجر اء المفاوضات بين الإتحاد الأوروبي (EU) و IASB بخصوص تطبيق القيمة

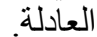

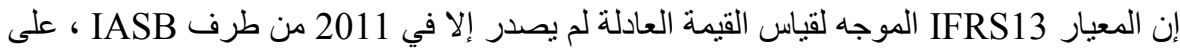

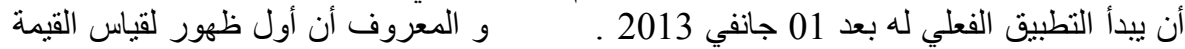

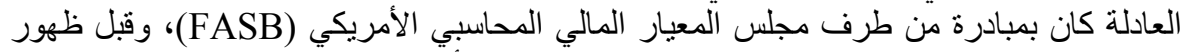

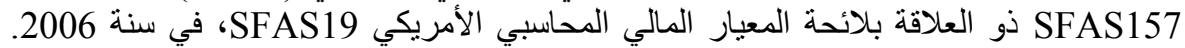

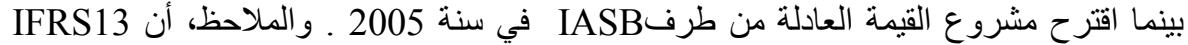

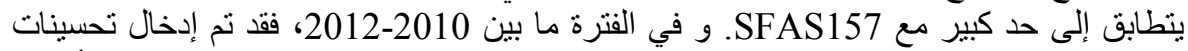

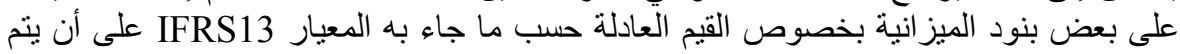

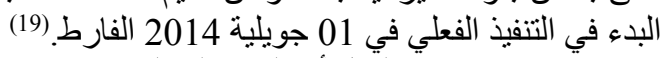

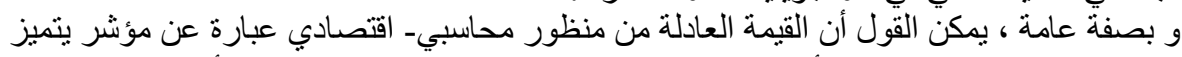

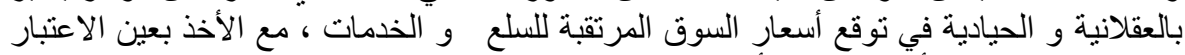

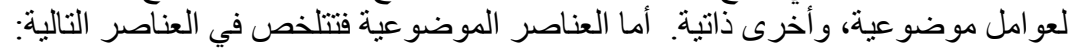

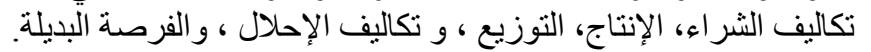

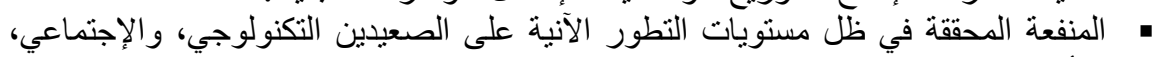

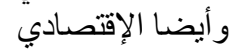

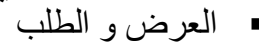

من جهة أخرى، تتلخص العناصر الذاتية في : الخطر، العائد و تكلفة رأس المال، المنفعة الذاتية.

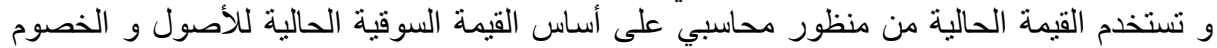
(Mark-to Market)

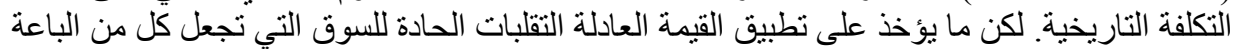

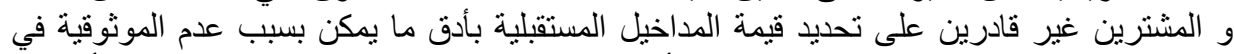

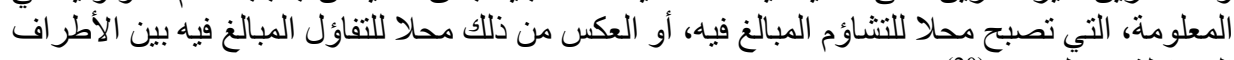

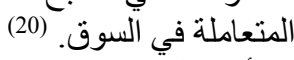

4- أثر تطبيق (IFRS) على جودة المعلومة المحاسبية و المؤشرات المالية 4 - 1 جودة الأرباح و القو ائم المالية

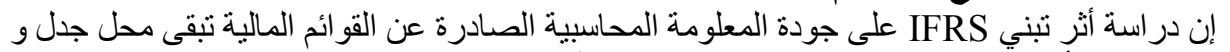

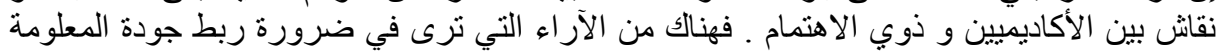

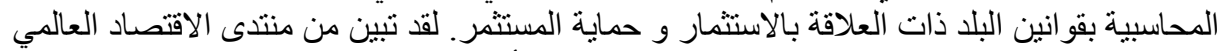

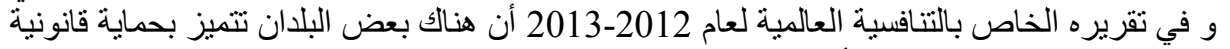

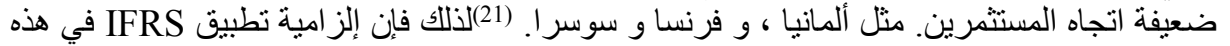

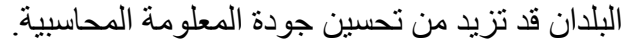

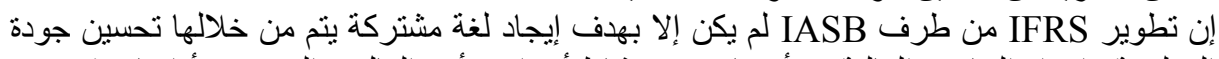

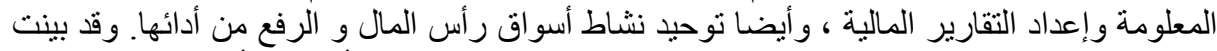

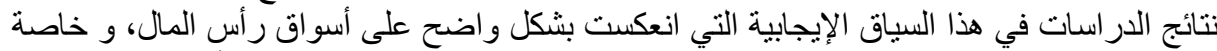

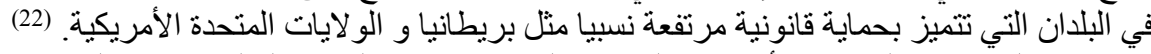

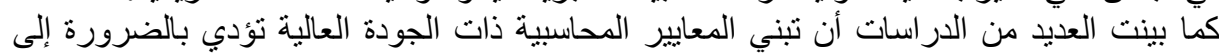

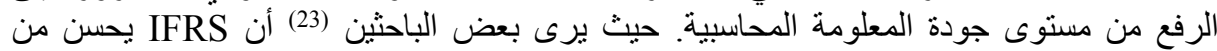

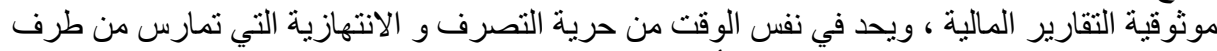

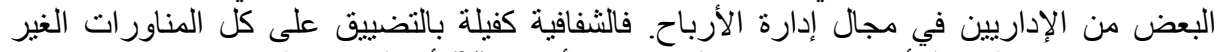

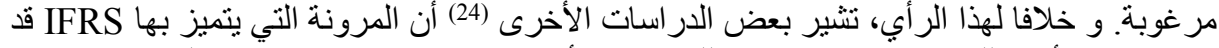
يمنح فرصة أكبر للمحاسبين و الإداريين للتلاعب بالأرباح و إدارتها بطريقة غير سليمة. بينما برى بلئ 
رأي آخر، أن تطبيق IFRS في مقابل النظام الدحاسبي المحلي (GAAP) في بلا كألمانيا، مثلا، لم إلارئ

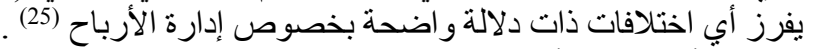

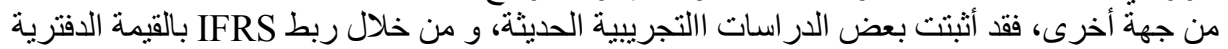

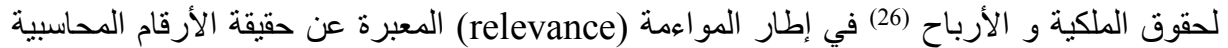

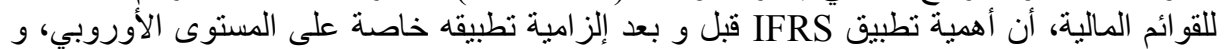

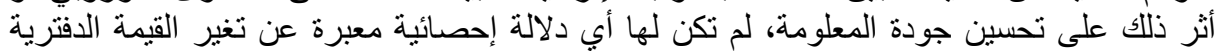

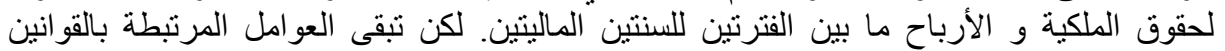

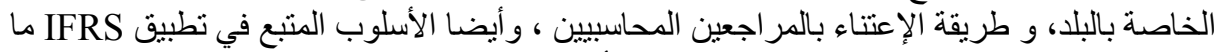

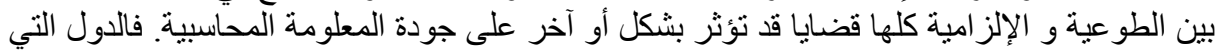

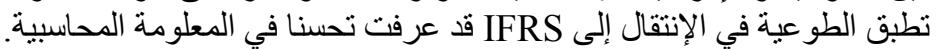

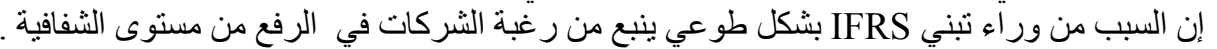
كما أن إعداد التقارير وفق IFRS يرتبط إيجابيا بحجم الثركة، و و أيضاً إلى عدد الأسو اق التي التي تمنتلك

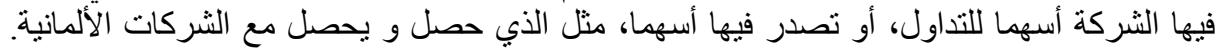

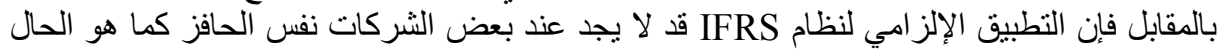

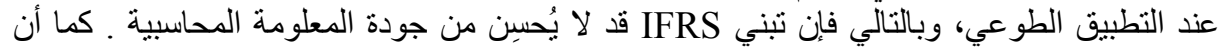

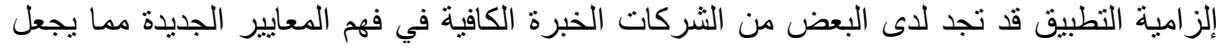

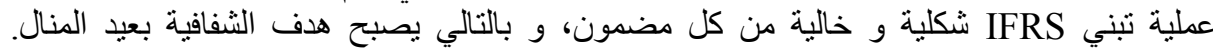

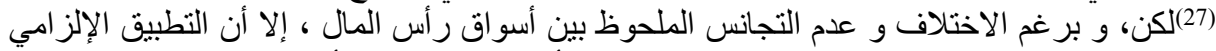

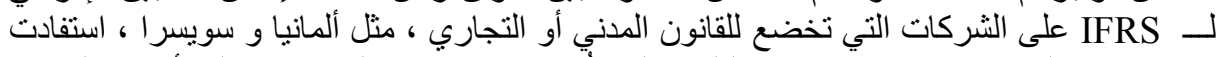

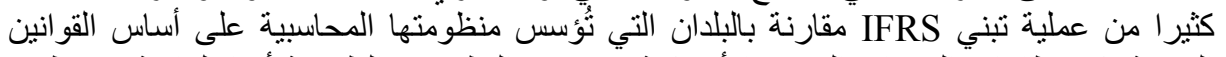

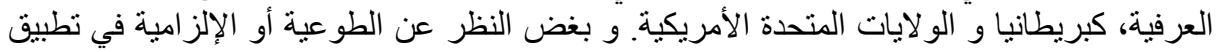

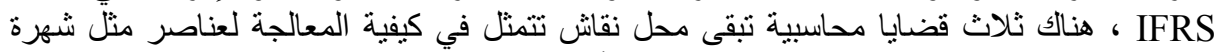

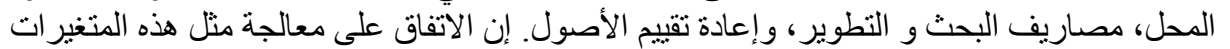

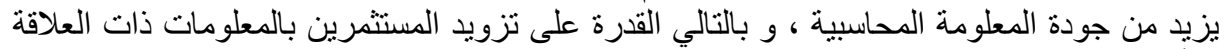

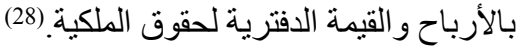

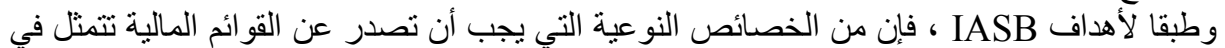

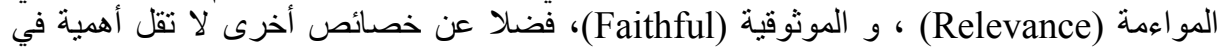

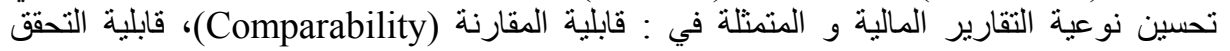

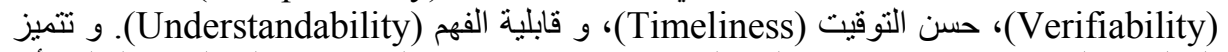

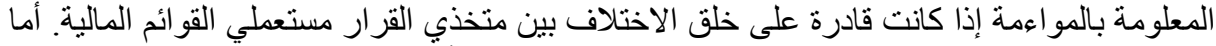

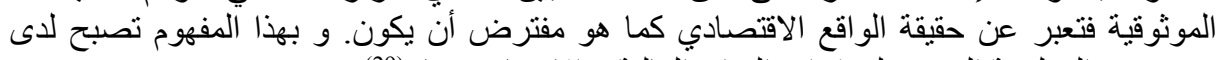

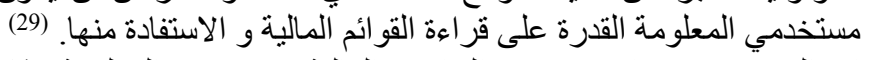

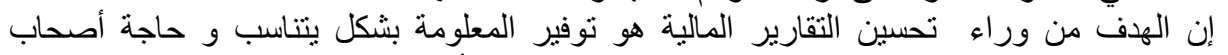

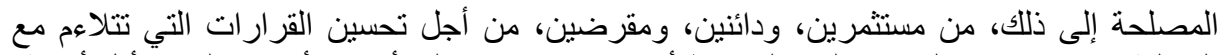

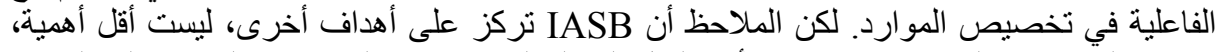

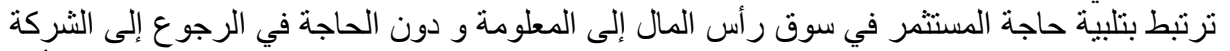

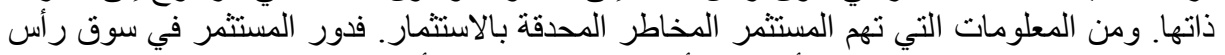

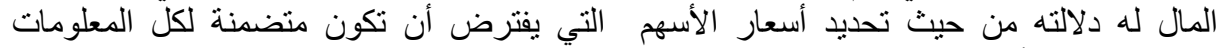

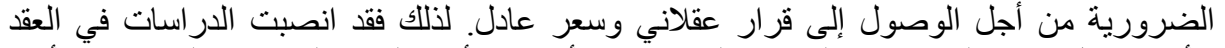

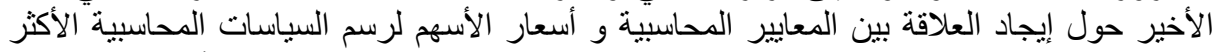

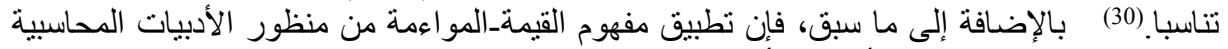

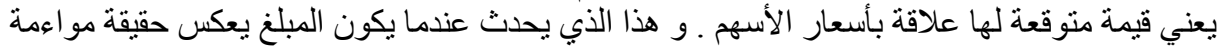


المعلومة التي تفيد المستثمر في تقييم الثركة ، وأيضا تكون ذات مصداقية تعكس السعر العادل للسهر.

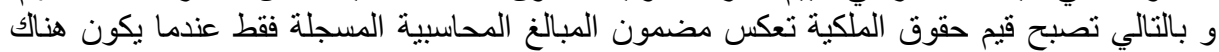

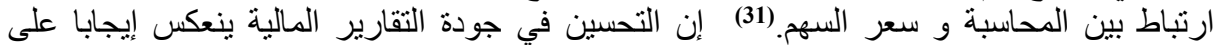

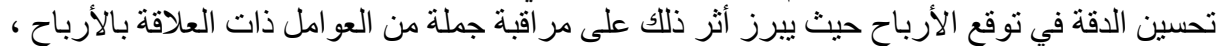

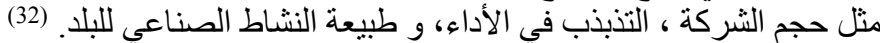

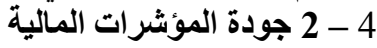

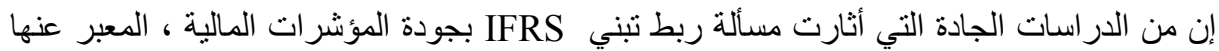

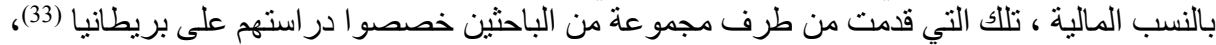

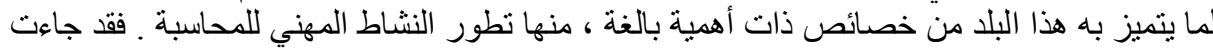

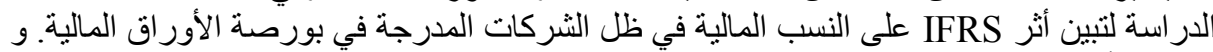

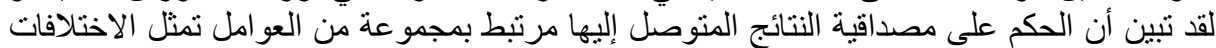

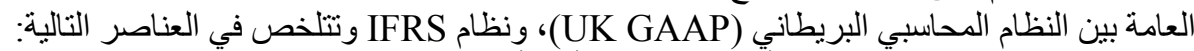
ـ نظام التمويل للبلا (تمويل على أستاس السندات، أو الأسهر)،

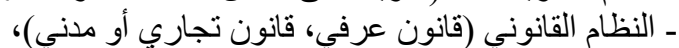

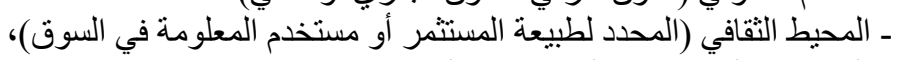

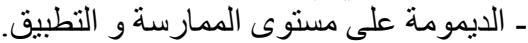
لقد نم استخدام عددا من النسب المالية تم انتقاؤ ها بعناية للتعبير عن مدى ارتباطها بنظام IFRS في

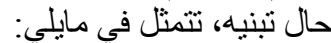

ـ هامش الربح التشغيلي ( OPM: Operating Margin) = الربح التشغيلي/ المبيعات ـالعائد على حقوق الملكية (ROE: Return on Equity) = الربح الربح الصافي/ حقوق الملكية الرية ـالعائد على الأصول المستثمرة ( ROIC: Return on Invested Capital) التشغيلي/إجمالي الأصول المستثرة السترة ـالسيولة العامة ( CR= Current assets/ Current liabilities) = الأصول الأصول المتداولة/الخصوم

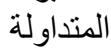
-سعر السهم إلى الأرباح (P/E : Price of share to Earning) =لتسعر السهم/الربح الصافي.

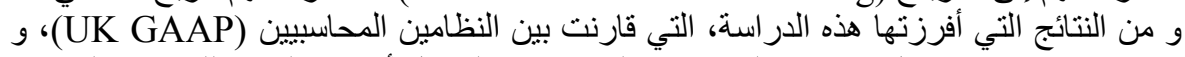
(UK IFRS) عن كل مؤشر، مع الإشارة أن هذه النتائج تمثل جزء فل فقط من النتائج الكلية التي توصلت إليها

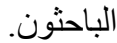

\begin{tabular}{|c|c|c|}
\hline \multicolumn{3}{|c|}{ الجدول رقم -2- } \\
\hline لمتوسط (UK IFRS) & المتوسط (UK GAAP) & النسب المالية \\
\hline 0.130 & 0.106 & OPM \\
\hline 0.270 & 0.185 & ROE \\
\hline 0.048 & 0.043 & ROIC \\
\hline 1.744 & 1.702 & CR \\
\hline 14.672 & 21.044 & $\mathrm{P} / \mathrm{E}$ \\
\hline
\end{tabular}


المصدر: , Lueg, Rainer, Punda, Pawel , and Burkert, Michael, (2014) , Op cit p245

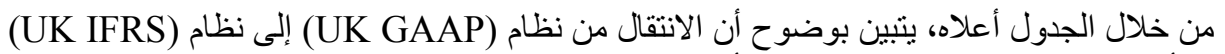

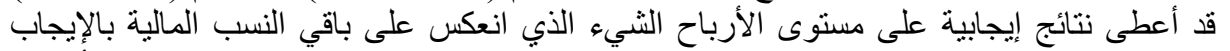

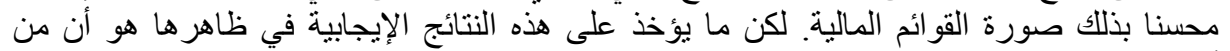

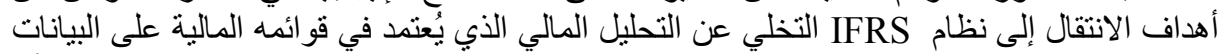

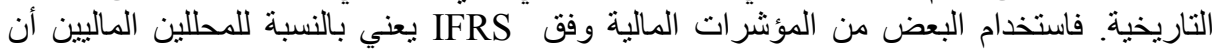

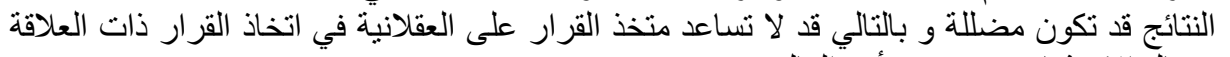

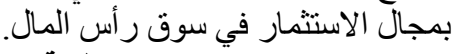

5-5 تجارب بعض الدول المطبقة لـنظام (IFRS)

5- 1 مجموعة الاول الأنجلوسكسونية (USA, UK)

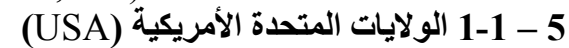

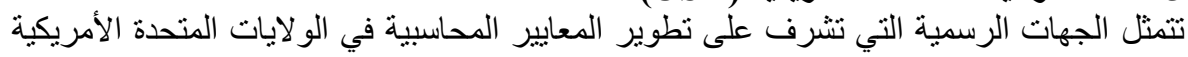

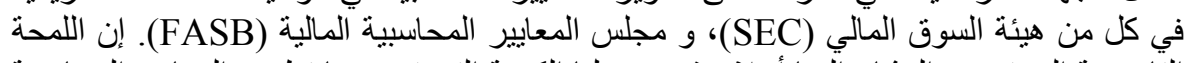

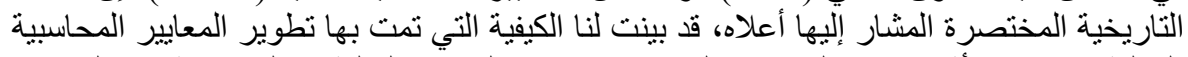

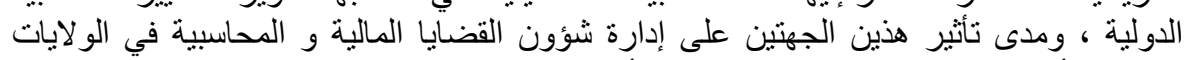

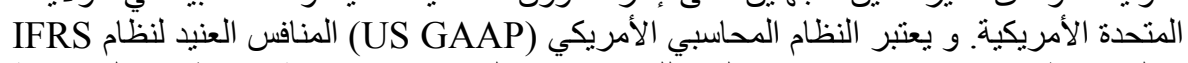

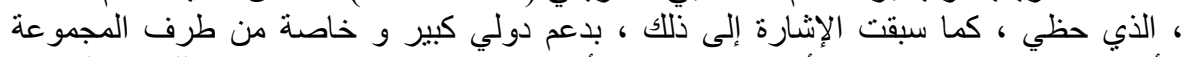

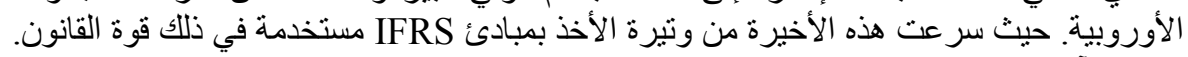

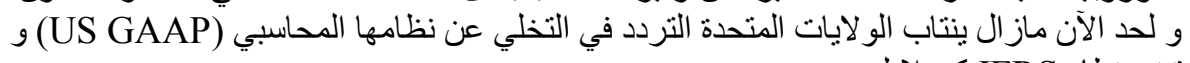

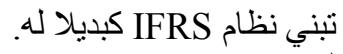
لقد كان في إمضاء مفكرة تفاهم بين (FASB) من جهة الو لايات المتحدة الأمريكية و بين (IASB)

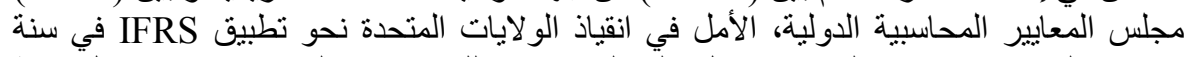

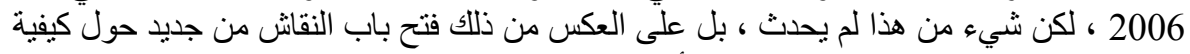

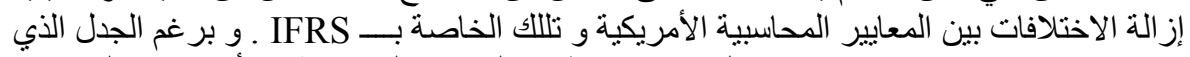

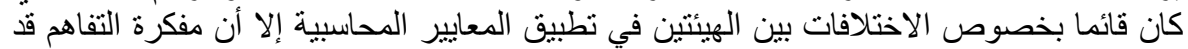

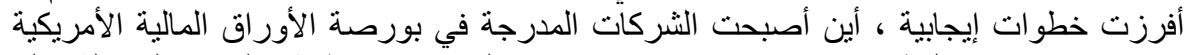

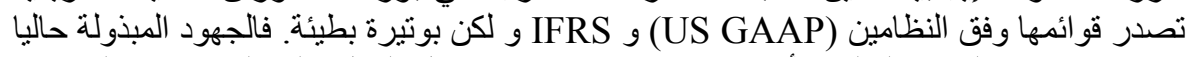

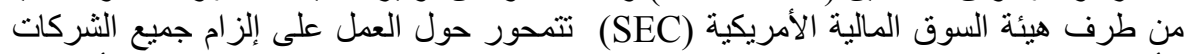

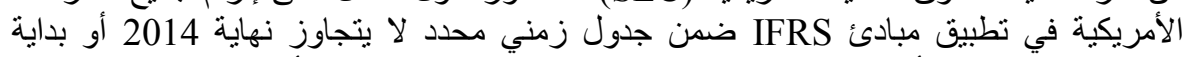

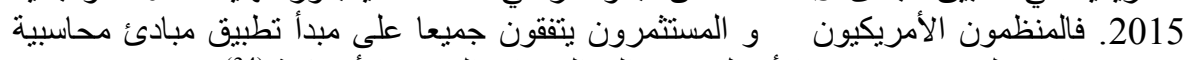

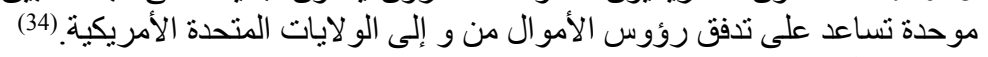
(UK)

تعتبر التجربة البريطانية في تطبيق IFRS متميزة و مثيرة للانتباه. فهي من جهة تنتمي للمدرسة

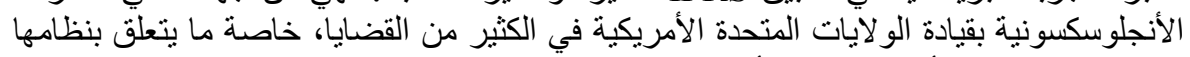

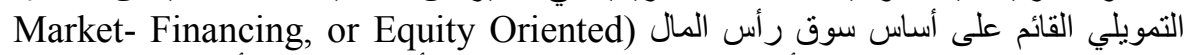

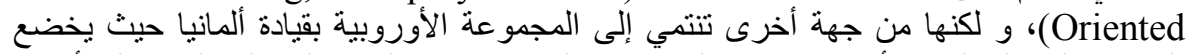

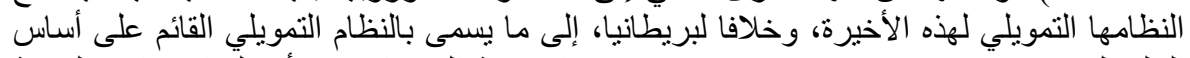

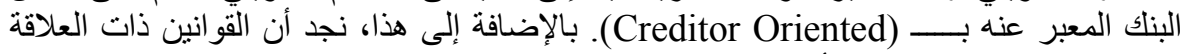

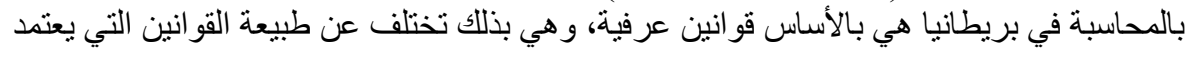


عليها في بلدان كفرنسا و ألمانيا، اللتين تستندان في توجيه نشاطاتهما الإقتصادي إلى تحكيم القانون

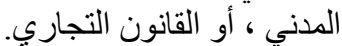

وعلاوة لما سبق ، بمكن القول أن بريطانيا قد اختلفت نسبيا عن المجموعة الأوروبية في تطبيق IFRS

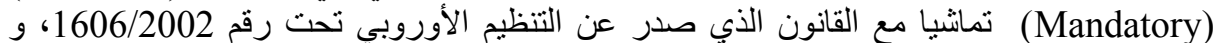

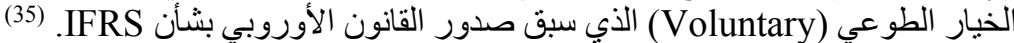

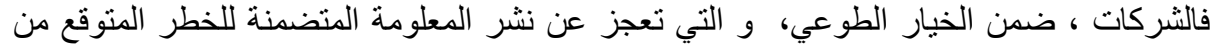

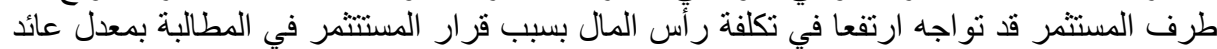

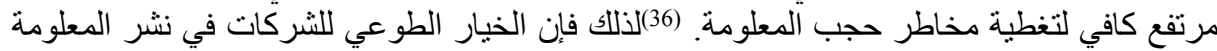

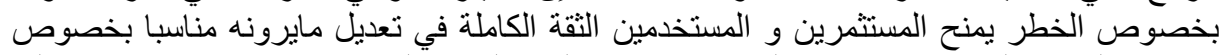

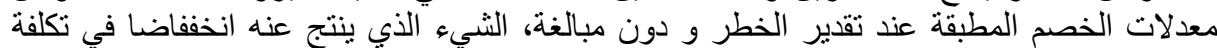

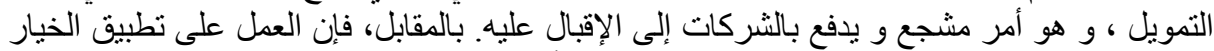

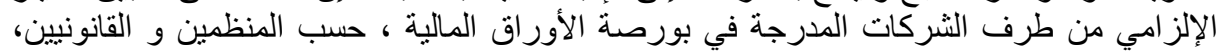

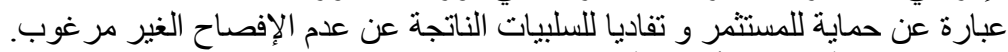

5- 2 مجموعة الدول الأوروبية (Germany, Switzerland)

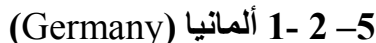

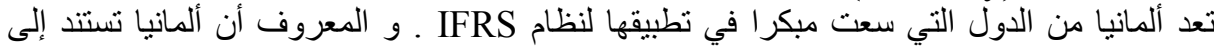

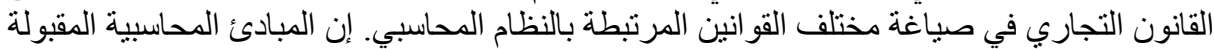

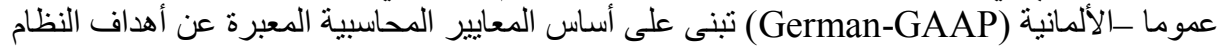

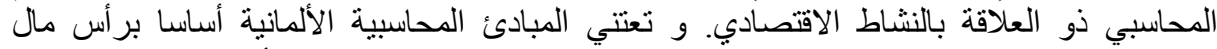

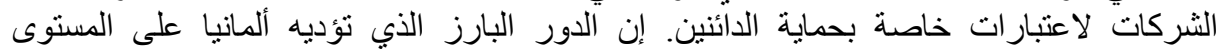

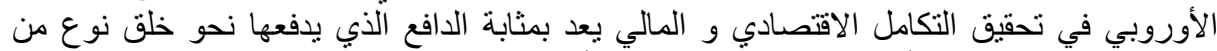

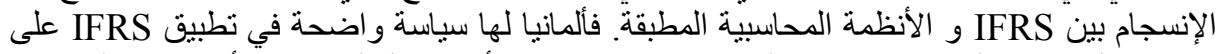

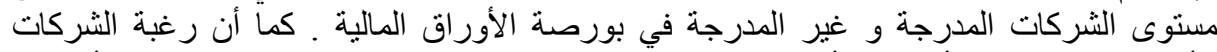

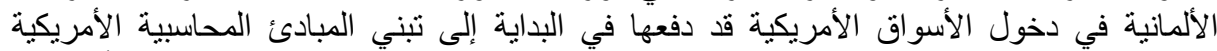

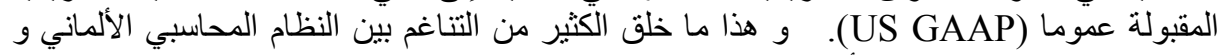

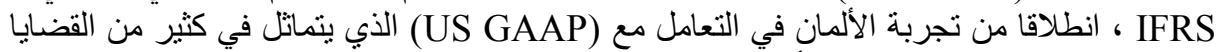

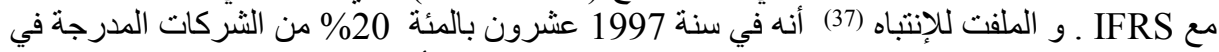

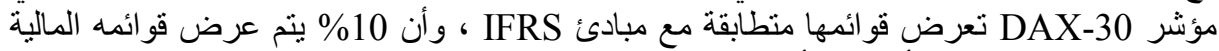

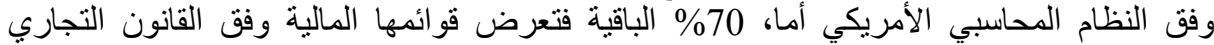

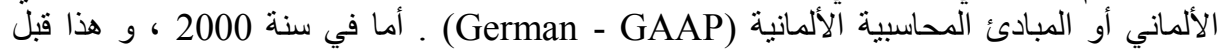

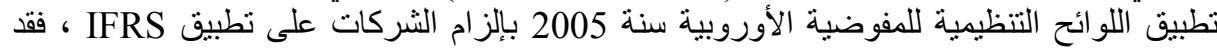

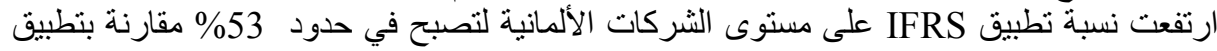

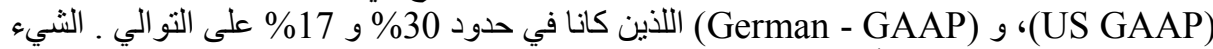

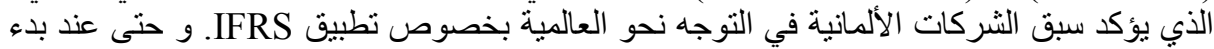

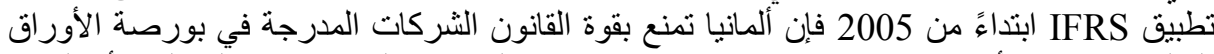
المالية من تطبيق أي منظومة محاسبية غير IFRS ، بينما الثركات الغير مدرجة فلقان الثها الحق أو الخيار

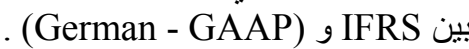

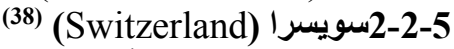

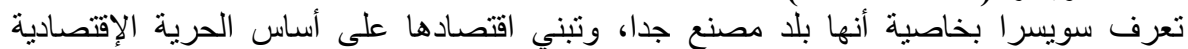

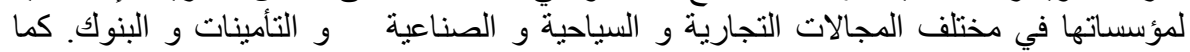




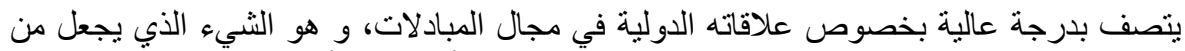
سويسر ا بلدا مؤهلا لتطبيق IFRS و بمرونة كبيرة قد لا تلقل أهمية عن ألمانيا.

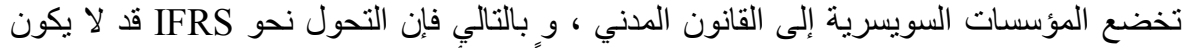

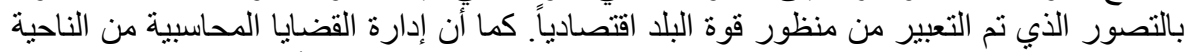

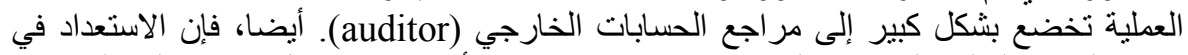

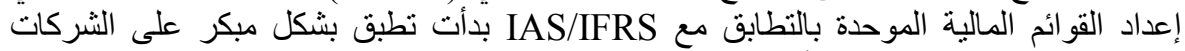

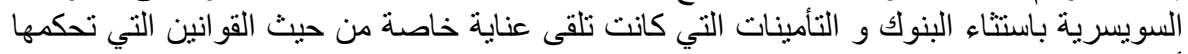

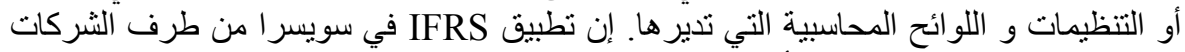

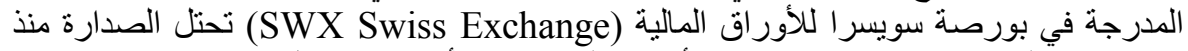

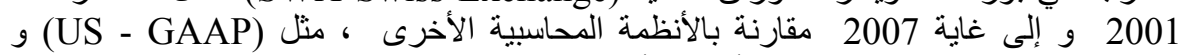

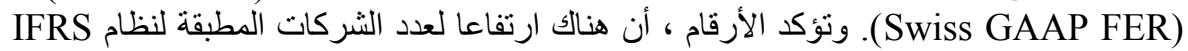

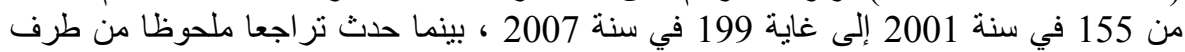

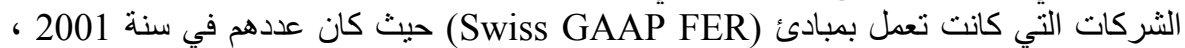

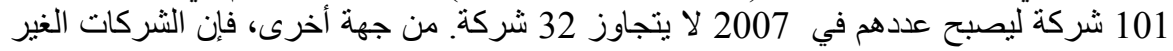

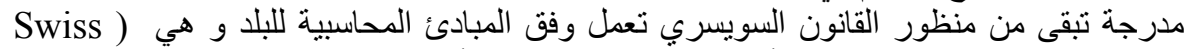
GAAP FER

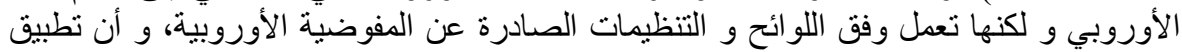

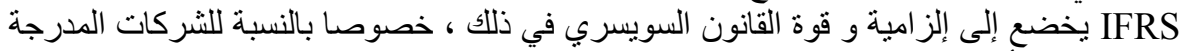
في بورصة الآوراق المالية.

BRICS: Brazil, Russian, India, China, and South Africa) 3 -5 مجموعة البرويل

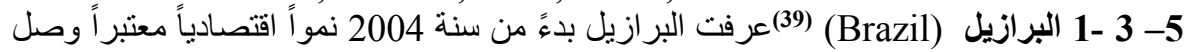

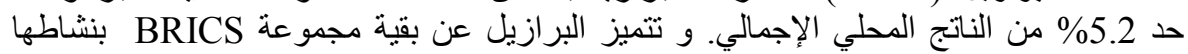

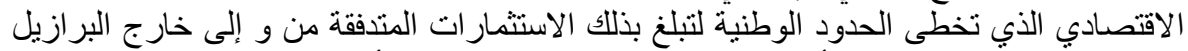

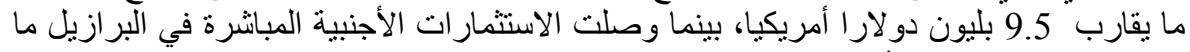

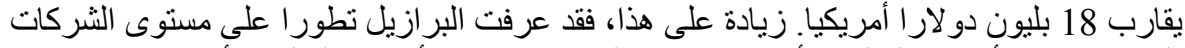

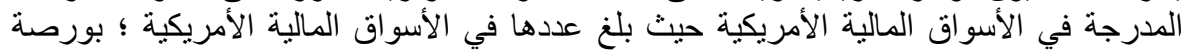

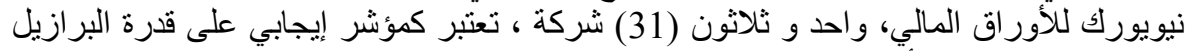

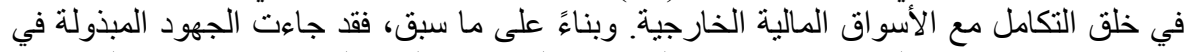

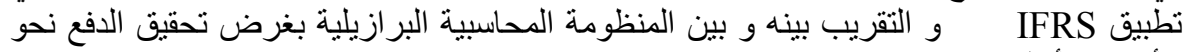

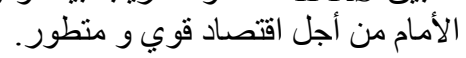
إن تطبيق IFRS من الناحية العملية ليس بالأمر السهل في بلد كالبرازيل ـ فالعو امل المرتبطة

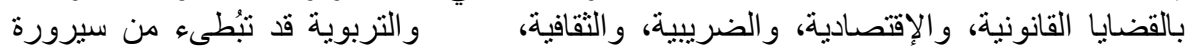

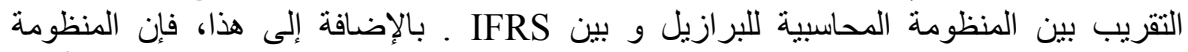

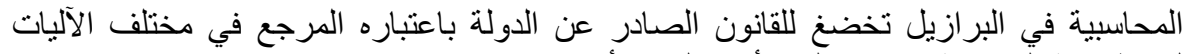

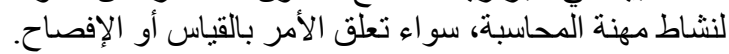

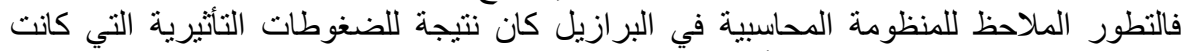

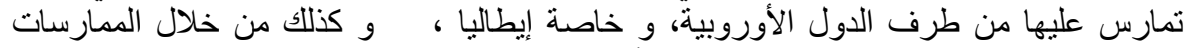

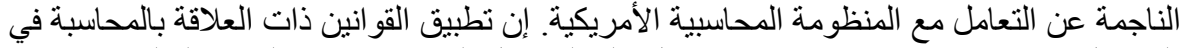

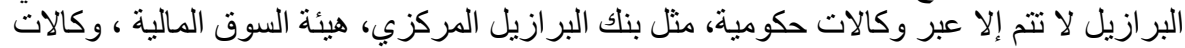

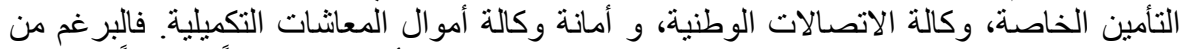

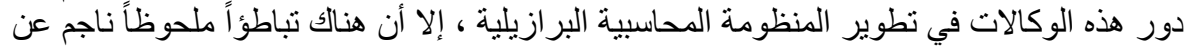


نقص التتسيق، وخاصة بين هيئة السوق المالي، وبنك البرازيل، وكذلك المصالح المفتشية لمر اقبة

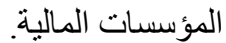

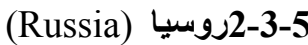

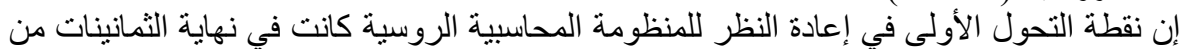

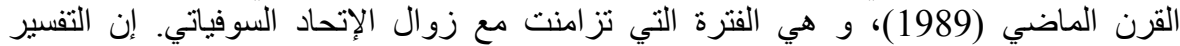

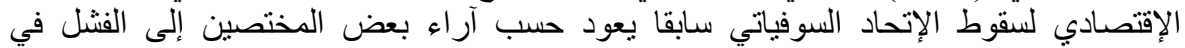

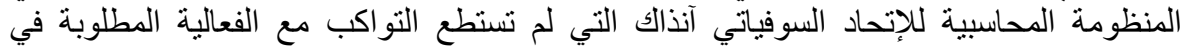

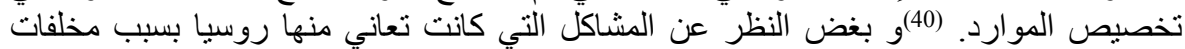

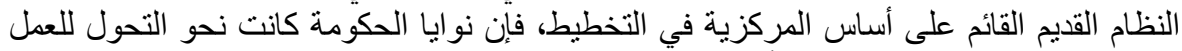

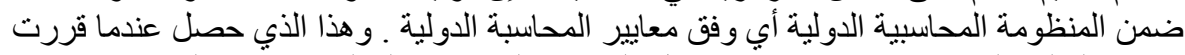

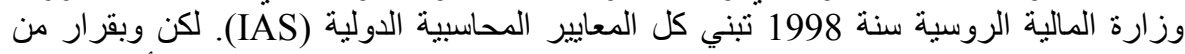

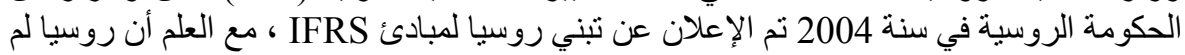

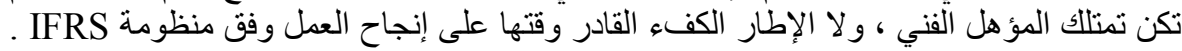

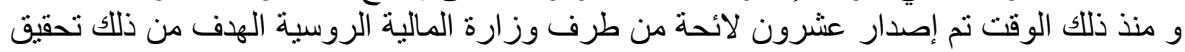

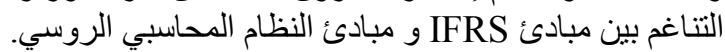

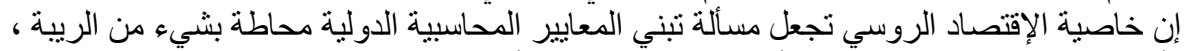

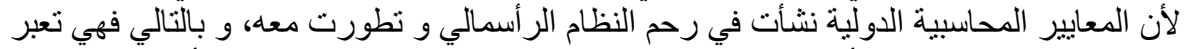

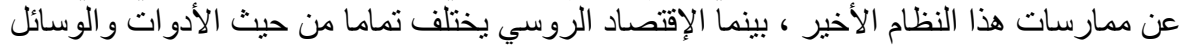

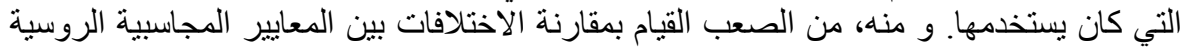
(RAS: Russia Accounting Standards)

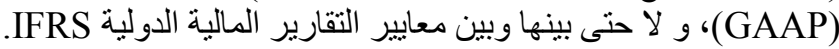

(India) 3- 3-5

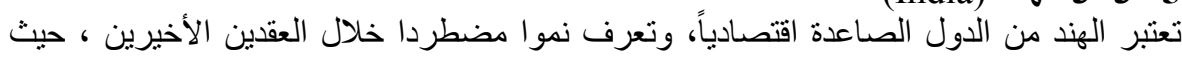

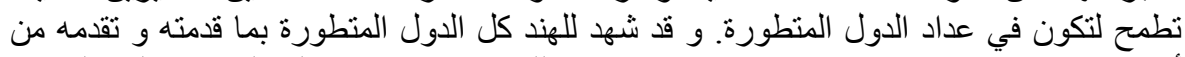

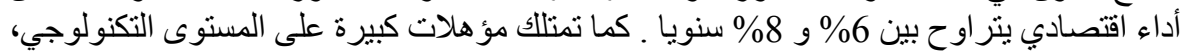

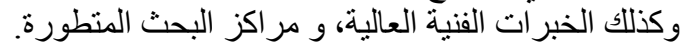

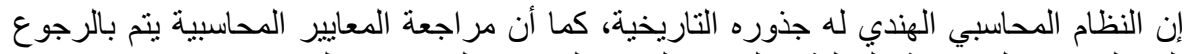

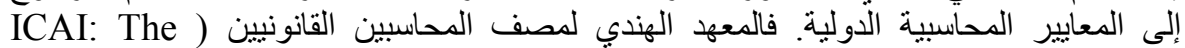
Institute of Chartered Accountants of India

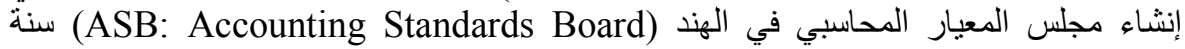

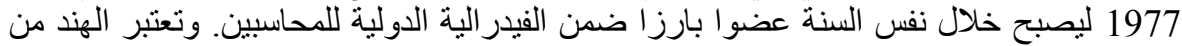

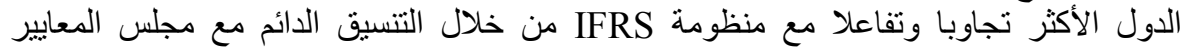

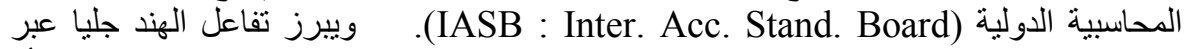
(ICAI)

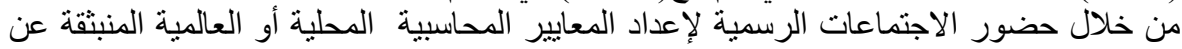

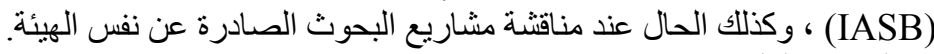

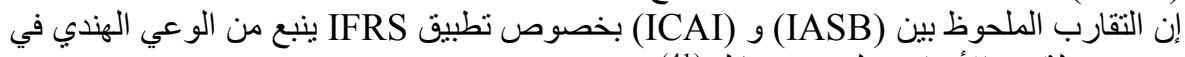
تحقيق جملة من الأهداف تتلخص فين النيمايلي (41) تحسين المعلومة المالية لاى المستثمرين عندما يتعلق الأمر بمقارنة القوائم المالية

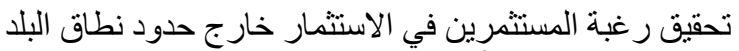

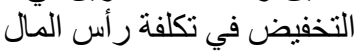
تحقيق الفعالية في تخصيص الموارد النيال 


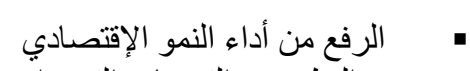

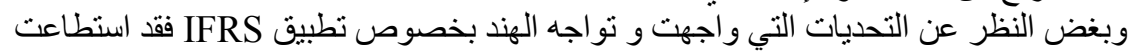

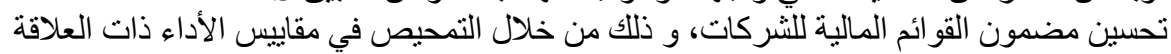

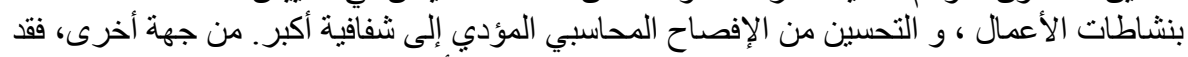

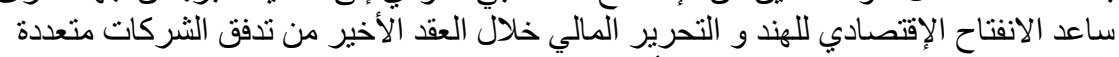

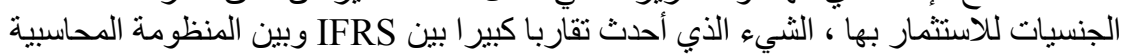

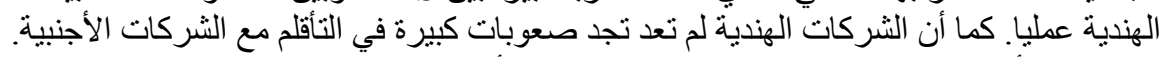

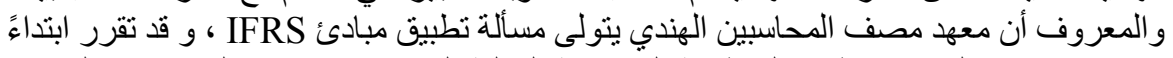

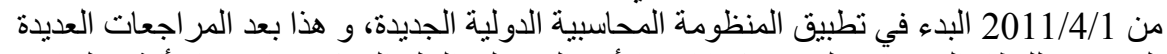

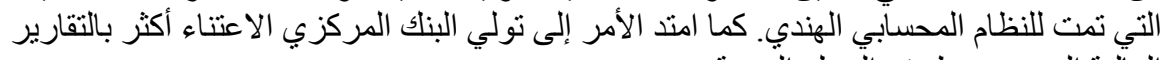

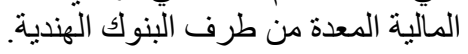

(China)

تعد الصين من الدول الصاعدة اقتصاديا ، و التي تنتمي بدور ها إلى مجمو عة (BRICS)

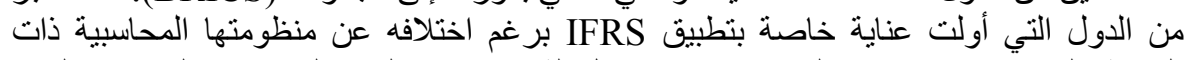

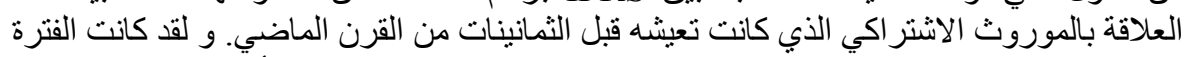

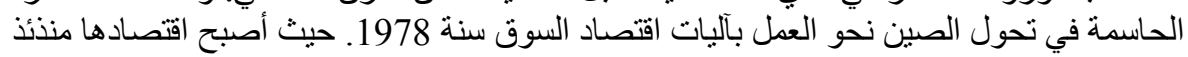

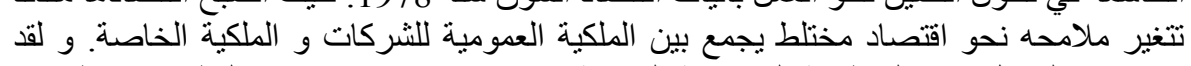

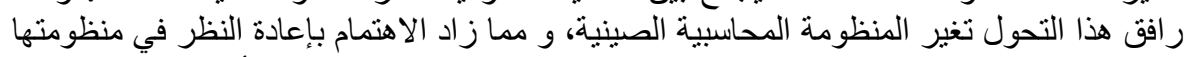

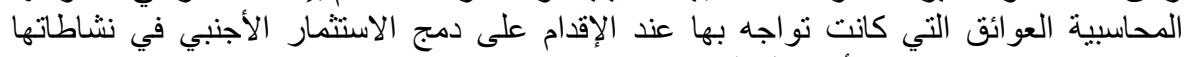

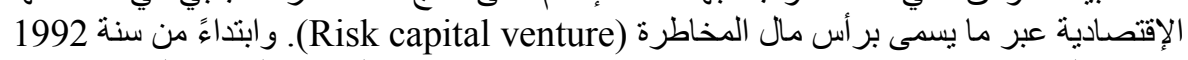

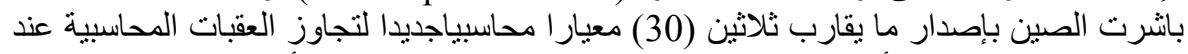

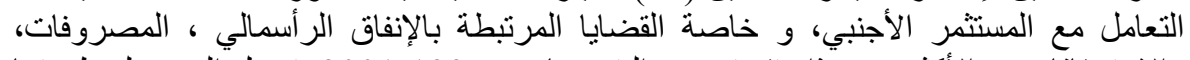

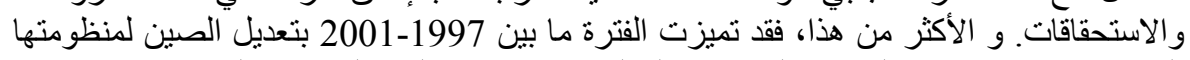

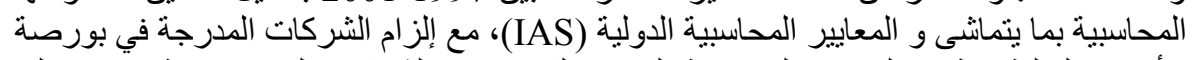

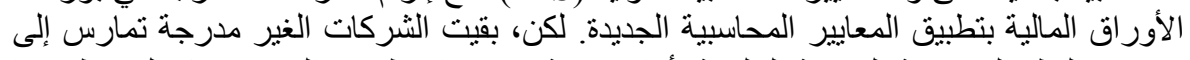

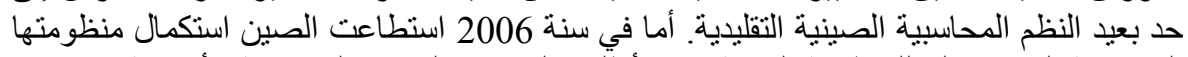

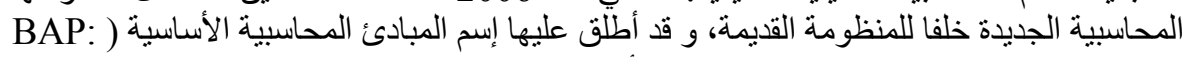
(Basics of Accounting Principles

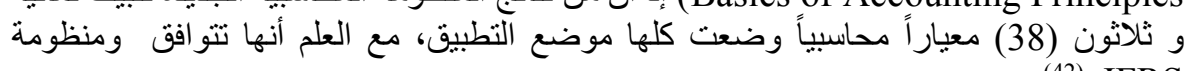

بالإضافة لما سبق، تعمل القوانين المحاسبية الصينية على الأخذ بمبادئ IFRS و لكن وفق ما يخدم

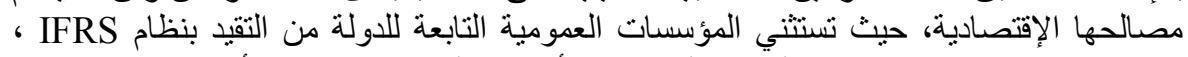

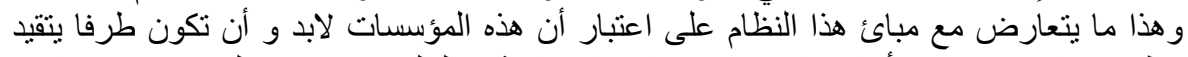

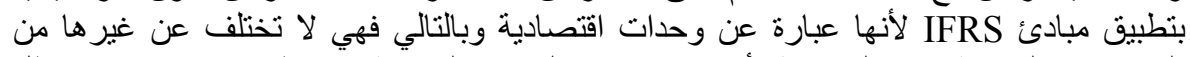

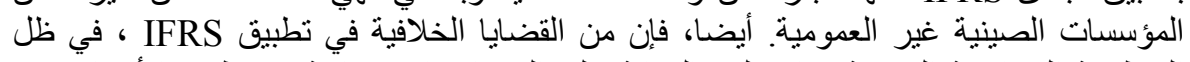

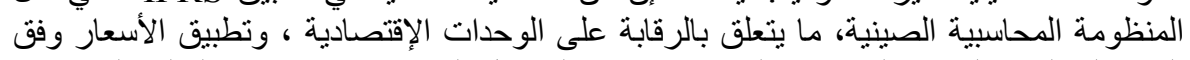

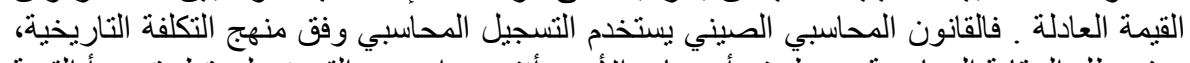

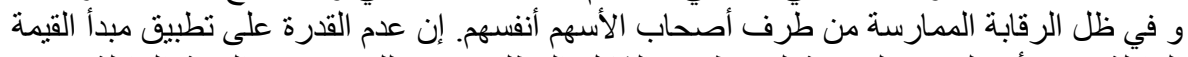

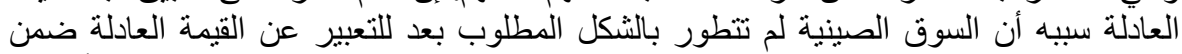

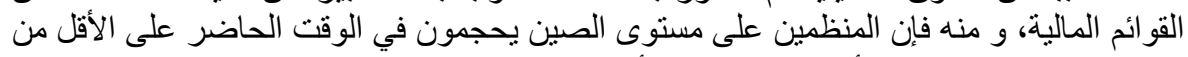

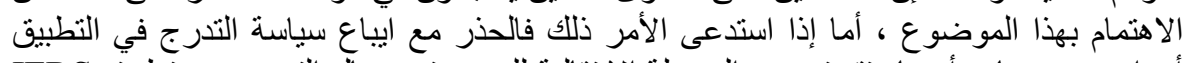

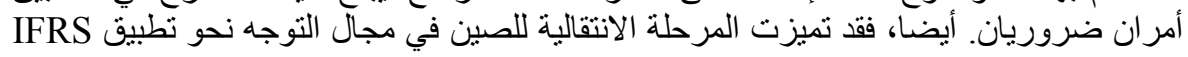




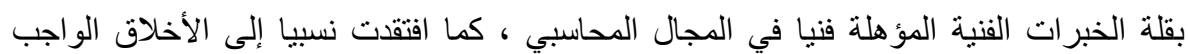

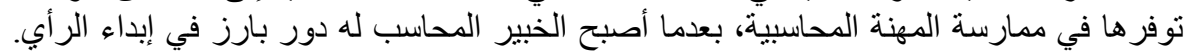

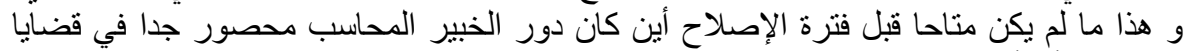

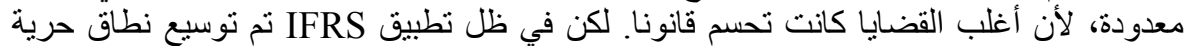

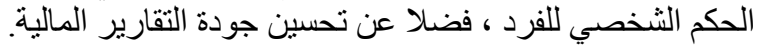

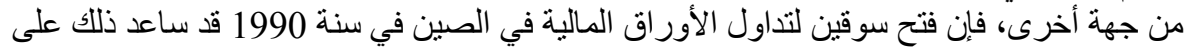

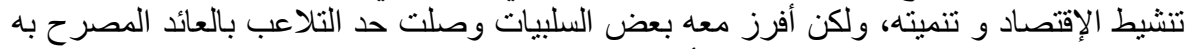

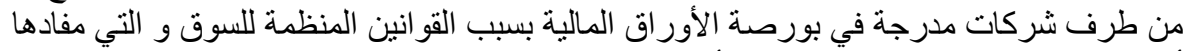

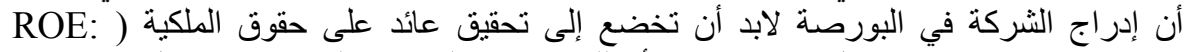
(Return on Equity

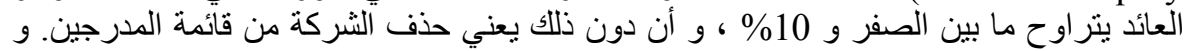

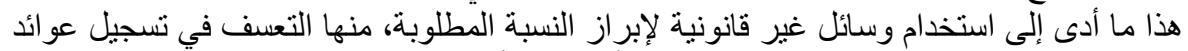

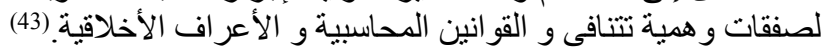

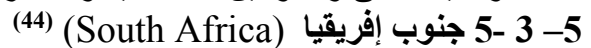

تعتبر جنوب إفريقيا قوة اقتصادية في إفريقيا ، يقدر الناتج المحلي الإجمالي بها أربعة أضعاف جميع الإنيا

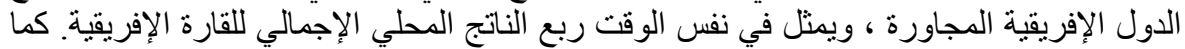

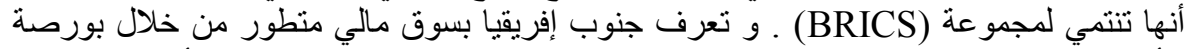

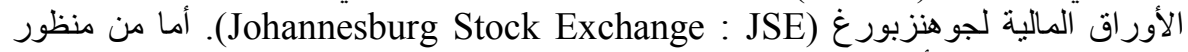
محاسبي فبها هيئتين أساسيتين تنمثلان في المعهد الجنوب إفريقي لمصف المحاسبين القانونيين ( و و مجلس (SAICA: The South African Institute of Chartered Accountants الممارسات المحاسبية (APB: Accounting Practices Board). أيضا، فإن بلدا كجنوب

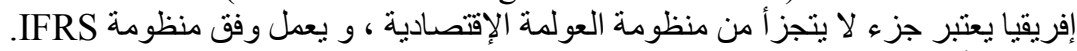

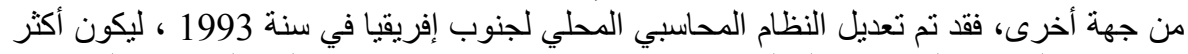

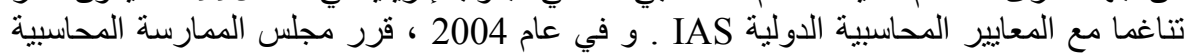
الإنتقال إلى تطبيق IFRS و اعتباره بمثابة المبادئ المحاسبية المقبولة عموما (APBAP)

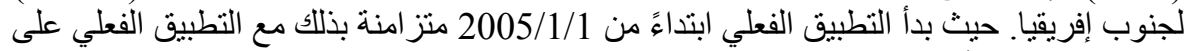

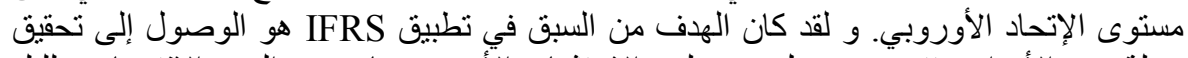

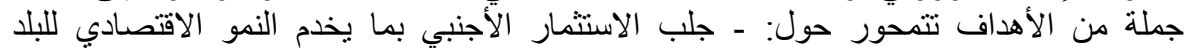

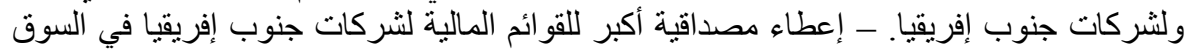

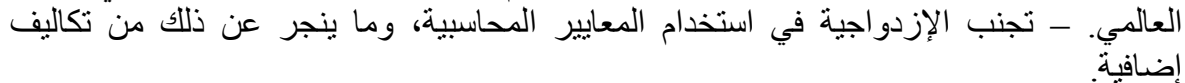

بالإضافة إلى ما سبق، أصدرت الهيئات المحاسبية و المالية المشرفة على تطبيق IFRS مرسوما

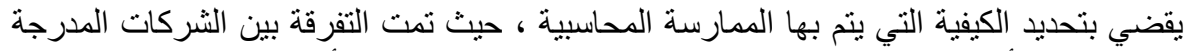

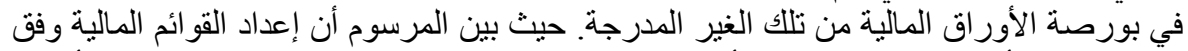

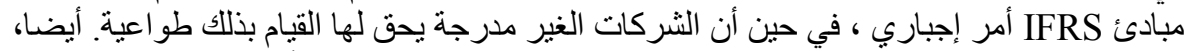

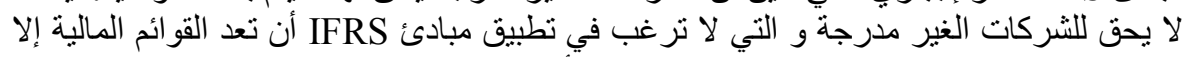

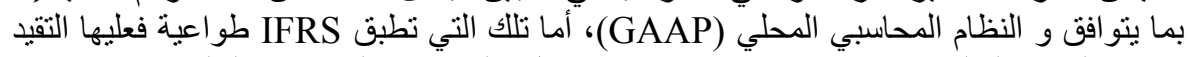

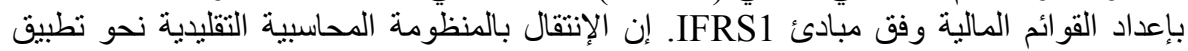

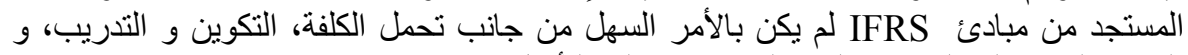
الحاجة الدائمة إلى الخبر ات الفنية الدحاسبية عالية التأهيل. 


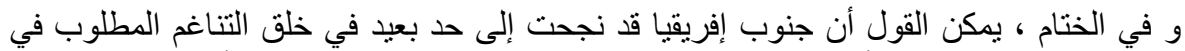

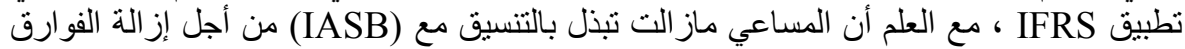
التي ماز الت عالقة بين المنظومنين المحاسبيتين.

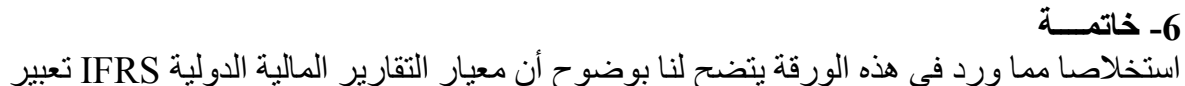

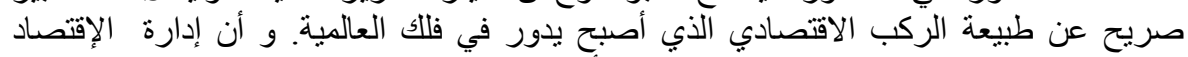

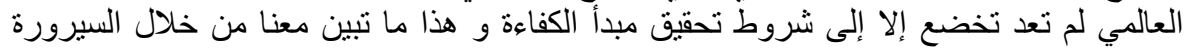

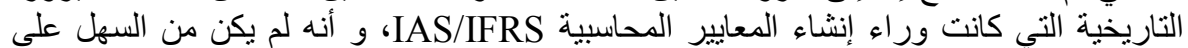

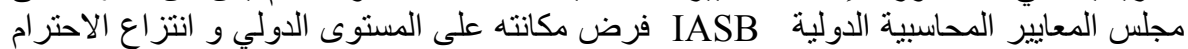

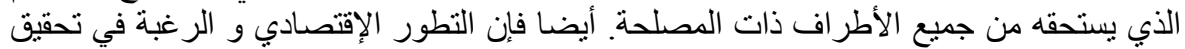

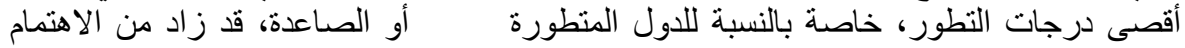
بتطوير المعايير المحاسبية. ومماسبق يمكن الخروج بالملاحظات و الاستنتاجات الآتية:

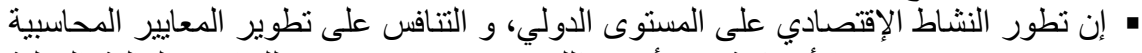

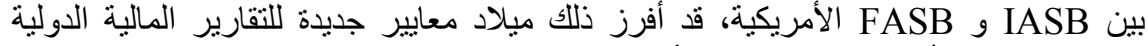

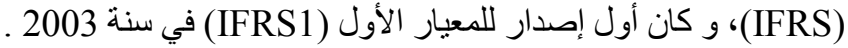

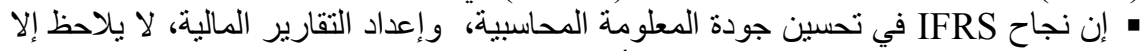

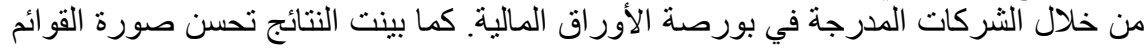

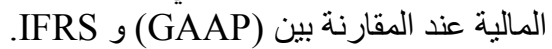

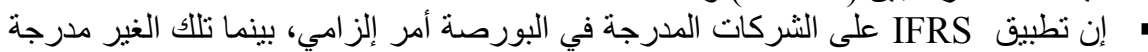

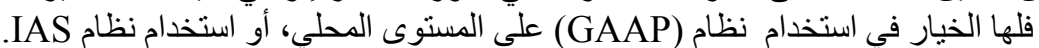

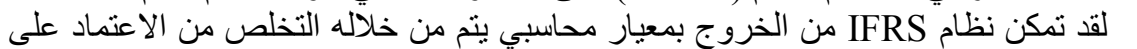

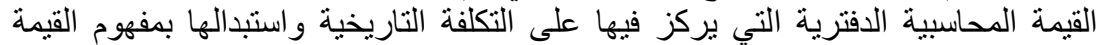

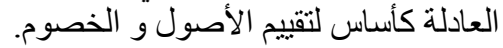

إن تبني مبدأ القيمة العادلة من خلال تطبيق نظام IFRS معناه ضرورة الألت التحسين في مخرجات

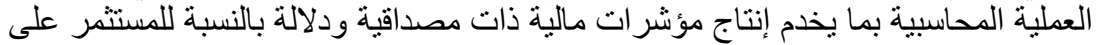
مستوى سوق الأور اق المالية. و هذا مايدعم صدق الفئ الفرضيتينين المقترحتين.

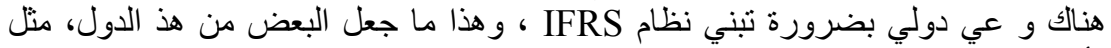

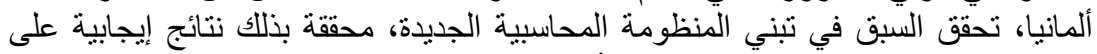

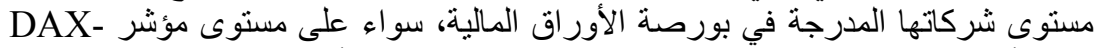

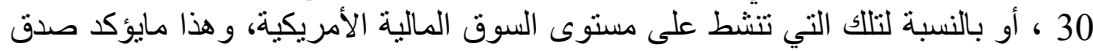

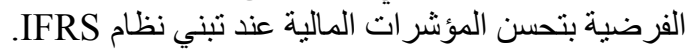

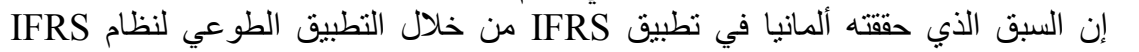

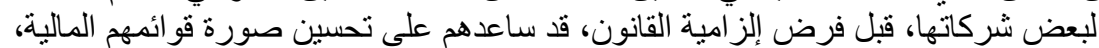

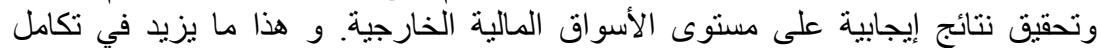
الأسواق المالية وتحقيق آفاق النمو الإقتصادي.

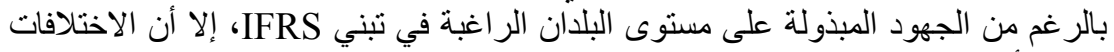

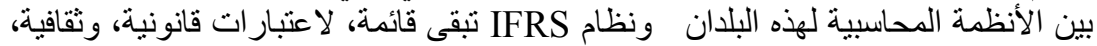

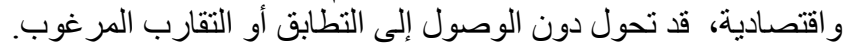
" مالطبق IFRS من طرف الكثير من البلدان ، بأسلو بين؛ الأسلوب الطوعي (Voluntary) و الأسلوب الإلزامي (Mandatory). كما أن عملية التطبيق تخضع إلى اللقانون المدني أو الو 


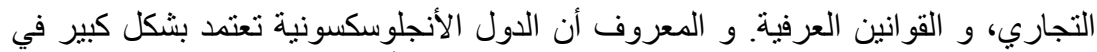

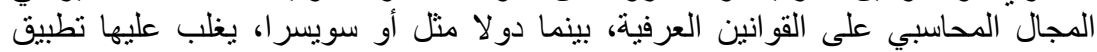

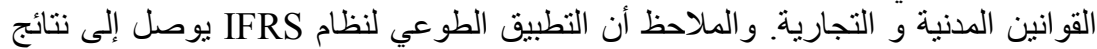
أحسن من جانب تحسين المعلومة المحاسبية والئن المالية.

تضطر الكثير من البلدان عند البداية في تطبيق IFRS اللجوء إلى استخدام الإزدواجية في التئي

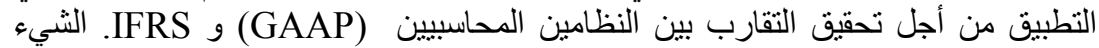

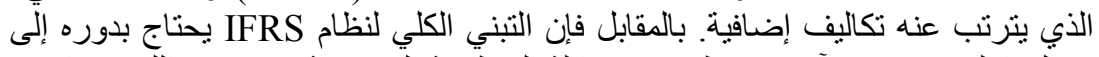

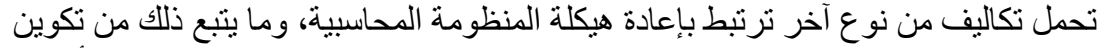

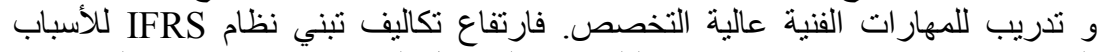

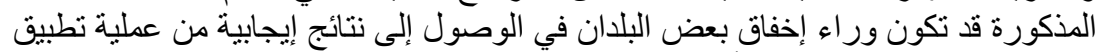

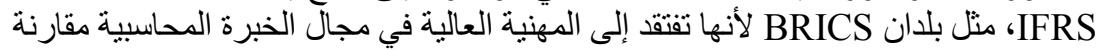

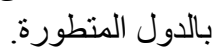
الهوامش:

1-Schenk,K.(2011), IFRS:the inevitable evolution of US Accounting Standards, www.honors.ufl.edu/apps/Thesis.aspx/.../1043., p1.

2-Ibid

3- لقد تقلا Henry Benson رئاسة لجنة المعايير الدحاسبية الدولية بعد المبادرة التي قام بها باستدعاء

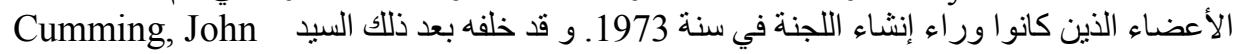
في سنة Paul

4-Zeff, Stephen A., (2012), The Evolution of the IASC into the IASB and the Challenges it Faces, The Accounting Review, Vol 87, N03, pp807-837.

5-Ibid 6- Schenk, K. (2011)Op cit , p5.

7-Casey, W. J. (1972), Toward common accounting standards, Speech to the Conference on Financial Reporting, Commission des Operations de Bourse ,Paris, May 19.Available at: http://www.sec.gov/ news/speech/1972/051972casey.pdf

8http://en.wikipedia.org/wiki/List_of_International_Financial_Reporting_Stand ards. Web. 10 sept. 2014

9-Zeff, Stephen A., Op cit, p813.

10- Berger, A. (2010), The development and status of enforcement in the European Union, Accounting in Europe, 7 (1), pp15-35.

11'Zeff, Stephen A., Op cit , p818 12-" http://www.ifrs.org/The+organisation/IASCF+and+IASB.htm."About the IFRS Foundation and the IASB.", IFRS. Web. 10 sept. 2014

13http://en.wikipedia.org/wiki/List_of_International_Financial_Reporting_Stan dards, Web. 10 sept. 2014 
14- Ernst \& Young LLP, (2013), US GAAP versus IFRS:The basics, (http://www.ey.com/Publication/vwLUAssetsAL/IFRSBasics BB2648 6Nove mber2013/\$FILE/IFRSBasics BB2648 6November2013.pdf), Web Sept 2014. 15-Palea, Vera , (2014), Are IFRS value-relevant for separate financial statements? Evidence from the Italian stock market, Journal of International Accounting, Auditing and Taxation 23 pp1-17.

16-Ibid

17- Ball, R. , (2006). International Financial Reporting Standards (IFRS): Pros and cons for investors. Accounting and Business Research: International Accounting Policy Forum, pp5-27.

18-Palea, Vera., (2013), IAS/IFRS and financial reporting quality: Lessons from the European experience, China Journal of Accounting Research , 6 , pp247-263

19- http://www.iasplus.com/en/standards/ifrs/ifrs13, Web September 2014 $20^{-}$http://en.wikipedia.org/wiki/Mark-to-market_accounting, Web September 2014

21- Nurul Houqe, Muhammad, Easton, Samuel, and van Zijl, Tony, (2014), Does mandatory IFRS adoption improve information quality in low investor protection countries?, Journal of International Accounting, Auditing and Taxation, 23 , pp87-97.

22-Ball, R. , (2006), Op cit, p7

23- Barth, M. E., Landsman, W. R., \& Lang, M. H. (2008), International accounting standards and accounting quality, Journal of Accounting Research, 43, pp467-498.

24- Burgsthaler, D., Hail, L., \& Leuz, C., (2006), The importance of reporting incentives: Earnings management in European private and public firms, The Accounting Review, 81, pp983-1016.

25- Van Tendeloo, B., \& Vanstrelen, A., (2005), Earnings management under German GAAP versus IFRS, The European Accounting Review, 14, pp155180.

26- Ahmed, Kamran, Chalmers, Keryn, and Khlif, Hichem, (2013),A Metaanalysis of IFRS Adoption Effects, The International Journal of Accounting, 48, pp173-217.

27- Daske, H., Hail, L., Leuz, C., Verdi, R., (2013), Adopting a label: heterogeneity in the economic consequences around IAS/IFRS adoptions, Journal of Accounting Research 51 (3), pp 495-547.

$28^{-}$Prather-Kinsey, J., Jermakowicz, E., Vongphanith, T., (2008), Capital Market consequences Of European Firms' Mandatory Adoption of IFRS, Working Paper, University of Missouri.

29- Latridis, George, (2010),IFRS and the quality of financial statement information, International Review of Financial Analysis, 19, pp193-204. 
30- Bartov, E., Goldberg, S.R., Kim, M. (2005), Comparative Value Relevance Among German, U.S., and International Accounting Standards: A German Stock Market Perspective, Journal of Accounting, Auditing \& Finance, 20(2), pp95-119.

31- Barth, M. E., Landsman, W. R., \& Lang, M. H. (2008), Op cit, p480

32- Jiao,T., Koning, M., Mertens, G., \& Roosenboom, P., (2012), Mandatory IFRS adoption and its impact on analysts' forecasts, International Review of Financial Analysis, 21 (1), pp56-63.

33- Lueg, Rainer, Punda, Pawel , and Burkert, Michael, (2014), Does transition to IFRS substantially affect key financial ratios in shareholderoriented common law regimes? Evidence from the UK, Advances in Accounting, incorporating Advances in International Accounting, 30, pp241250

34- Kosarkoska, Desa, and Mircheska, Irina, (2012), The main process in the international financial reporting at the beginning of 21 st century, Proceedia Social and Behavioral Sciences, 44 , pp241 - 249.

35- Cairns, David, Massoudi, Dianne, Taplin, Ross, and Tarca, Ann, (2011), IFRS fair value measurement and accounting policy choice in the United Kingdom and Australia, The British Accounting Review, 43 (2011) pp1-21. 36- Kothari, S., Li, X., \& Short, J. (2009), The effect of disclosure by management, analysts, and business press on cost of capital, return volatility, and analysts forecast: Study using content analysis, The Accounting Review, 84(5), pp1639-1670.

37- UNCTAD(United Nations Conference on Trade ), Review of practical implementation issues of International Financial Reporting Standards: Case study in Germany, Geneva, 10-12 October 2006.

38-UNCTAD, Review of practical implementation issues relating to international financial reporting standards: Case study of Switzerland, Geneva, 4-6 November 2008.

39- UNCTAD, Review of practical implementation issues of International Financial Reporting Standards: Case study of Brazil, Geneva, 10-12 October 2006.

40- Robert W. McGee, and Galina G. Preobragenskaya, (2004), Problems of Implementing International Accounting Standards in a Transition Economy: A Case Study of Russia, Presented at the 8th International Conference on Global Business and Economic Development, Guadalajara, Mexico, January 7-10. $41^{-}$UNCTAD, Review of practical implementation issues of International Financial Reporting Standards: Case study of India, Geneva, 10-12 October 2006.

42- Ding, Yuan, and Su,Xijia, (2008), Implementation of IFRS in a regulated market, J. Account. Public Policy, 27, pp 474-479.

43- Ibid, p 476. 
44- UNCTAD, Review of practical implementation issues of International

Financial Reporting Standards: Case study of South Africa, Geneva, 30

October-1 November 2007. 